\title{
Mechanisms Underlying the Anti-Suicidal Treatment Potential of Buprenorphine
}

\author{
Courtney M. Cameron ${ }^{1,2,3,4}$, Steven Nieto ${ }^{5}$, Lucienne Bosler ${ }^{2}$, Megan Wong ${ }^{2}$, Isabel Bishop ${ }^{2}$, \\ Larissa Mooney ${ }^{1,3,4}$ and Catherine M. Cahill ${ }^{1,2,3,4 *}$ \\ ${ }^{1}$ Department of Psychiatry and Biobehavioral Sciences, University of California, Los Angeles, Los Angeles, CA, United States, \\ ${ }^{2}$ Shirley and Stefan Hatos Center for Neuropharmacology, University of California, Los Angeles, Los Angeles, CA, United States, \\ ${ }^{3}$ Semel Institute for Neuroscience and Human Behavior, University of California, Los Angeles, Los Angeles, CA, United States, \\ ${ }^{4}$ David Geffen School of Medicine, University of California, Los Angeles, Los Angeles, CA, United States, ${ }^{5}$ Department of \\ Psychology, University of California, Los Angeles, Los Angeles, CA, United States
}

Death by suicide is a global epidemic with over $800 \mathrm{~K}$ suicidal deaths worlwide in 2012. Suicide is the 10th leading cause of death among Americans and more than $44 \mathrm{~K}$ people died by suicide in 2019 in the United States. Patients with chronic pain, including, but not limited to, those with substance use disorders, are particularly vulnerable. Chronic pain patients have twice the risk of death by suicide compared to those without pain, and $50 \%$ of chronic pain patients report that they have considered suicide at some point due to their pain. The kappa opioid system is implicated in negative mood states including dysphoria, depression, and anxiety, and recent evidence shows that chronic pain increases the function of this system in limbic brain regions important for affect and motivation.

OPEN ACCESS

Edited by:

Emmanuel Onaivi,

William Paterson University,

United States

Reviewed by:

Chloe Jordan

McLean Hospital, United States Lawrence Toll,

Florida Atlantic University,

United States

*Correspondence:

Catherine M. Cahill

cmcahill@ucla.edu

Received: 10 May 2021 Accepted: 30 June 2021 Published: 03 August 2021

Citation:

Cameron CM, Nieto S, Bosler L, Wong M, Bishop I, Mooney L and

Cahill CM (2021) Mechanisms Underlying the Anti-Suicidal Treatment

Potential of Buprenorphine.

Adv. Drug. Alco. Res. 1:10009.

doi: 10.3389/adar.2021.10009
Additionally, dynorphin, the endogenous ligand that activates the kappa opioid receptor is increased in the caudate putamen of human suicide victims. A potential treatment for reducing suicidal ideation and suicidal attempts is buprenorphine. Buprenorphine, a partial mu opioid agonist with kappa opioid antagonist properties, reduced suicidal ideation in chronic pain patients with and without an opioid use disorder. This review will highlight the clinical and preclinical evidence to support the use of buprenorphine in mitigating pain-induced negative affective states and suicidal thoughts, where these effects are at least partially mediated via its kappa antagonist properties.

Keywords: suicide, suicidal ideation, kappa opioid, addiction, pain, opioid use disorder, anhedonia, dysphoria

\section{INTRODUCTION}

Suicide is a pressing public health issue that accounts for more than 800,000 deaths per year globally [1]. In the United States, it is one of the 10 leading causes of death claiming more than 47,000 lives in 2019 , and the second leading cause of death in people aged 10 to 34 [2]. The rates of suicide have risen more than 30\% between 1999-2019. The United States Surgeon General and Department of Health and Human Services have recently issued a call to action to implement the National Strategy for Suicide Prevention that includes calls for treatment access to those that need it [3]. Important, for this review, is that chronic pain is second only to bipolar disorder as the major cause of suicide among all medical illnesses $[4,5]$. Suicide is typically preceded by suicidal ideation-persistent thoughts about wanting to kill oneself. While suicidal ideation only rarely leads to the completion of suicide (death), 
it is an important clinical marker, and prior suicide attempt is the single strongest risk factor for future suicidal behaviors and death by suicide [6].

Recently, there has been a dramatic increase in the prevalence of suicidal ideation during the COVID-19 pandemic and subsequent mitigation activities, including social distancing and stay-at-home orders [7, 8]. In June 2020, 10.7\% of adults reported thoughts of suicide compared to $4.3 \%$ of adults in 2018 [9]. Fortunately, suicide rates themselves have remained unchanged or declined early in the pandemic [10]. However, the management of patients suffering from suicidal ideation represents a rapidly growing clinical challenge. There are currently few pharmacological treatments available that specifically alleviate suicidal ideation; therefore, research into this clinical problem has the potential to save many lives.

Suicidal ideation occurs in a subset of individuals with major depressive disorder (MDD); however, emerging evidence suggests that suicidal ideation may also represent a distinct behavioral disorder [11]. For example, improvements in suicidal ideation following ketamine treatment cannot be entirely explained by improvements in depression or anxiety [12]. Suicidality also often presents with mental health disorders other than depression. Substance use is a risk factor for suicide attempts, and individuals with substance use disorders have a 10-14 times greater risk of death by suicide compared to the general population [13-15]. Many substance overdoses may also be unrecognized suicides [16]. Some studies have demonstrated that anxiety disorder comorbidity with other mood disorders is a risk factor for suicide attempts, though this finding has been inconsistent [17]. The comorbidity of borderline personality disorder and depression is associated with an increase in the number and seriousness of suicide attempts [18].

Acute and chronic alcohol use also play major roles in suicidal behavior. Approximately $26 \%$ of suicide decedents who were tested for alcohol had intoxicating blood alcohol levels $(>0.08 \%)$ [19]. According to recent meta-analyses, which include casecontrol and cohort studies, individuals with alcohol use disorder (AUD) have three times greater odds of suicidal behavior compared to those without the disorder [20, 21]. Furthermore, AUD has been identified as the second most common mental disorder among suicide decedents [22].

Finally, suicidal ideation is highly prevalent in chronic pain patients [23-26], even when controlling for the subjective severity of pain symptoms [27-29] and the presence of other affective disorders [27, 30, 31]. For such patients, suicide is viewed as a means to alleviate overwhelming and intolerable painful internal states, and psychological and emotional pain have been considered essential for suicidal behavior [32, 33]. A recent metanalysis of 31 studies showed a significant link between physical pain and suicidal thoughts and behaviors, where physical pain was associated with lifetime death wish, current and lifetime suicidal ideation, suicide plan, and suicide attempts, as well as death [34]. Some of the predictors of suicidal ideation in chronic pain patients include mental defeat [35], insomnia [36], and pain catastrophizing [37], which are also risk factors for opioid use disorder. Suicidal ideation in chronic pain patients is associated with depression, anxiety and sleep disorders [38]. This review will highlight recent data that provides justification for further clinical trials to test the potential of buprenorphine as a treatment for suicidal ideation, particularly in chronic pain patients.

\section{The Affective (Emotional) Dimension of Pain and Suicidal Ideation}

Chronic pain has both sensory and emotional/affective components that, while distinct, share many of the same neurobiological substrates. Chronic pain often induces a persistent negative affective state, or "emotional pain," likely as a result of neuroadaptations in the brain's reward processing circuitry [39-41]. Chronic pain is also associated with the development of other disorders of impaired reward processing, including depression and substance use disorders [42]. The prevalence of suicidal ideation among pain patients suggests that it may be an expression of emotional pain. In fact, studies have found emotional pain to be the psychological variable most strongly associated with current suicidality, even more so than the presence of depressed mood or hopelessness [18, 43, 44].

The relationship between AUD and suicidality also suggests that suicidal ideation may be an expression of emotional pain. That AUD is often a key risk factor for suicidal behavior is likely due, at least in part, to alcohol-induced exacerbations in negative emotionality and alcohol-related negative consequences, particularly in interpersonal domains [45]. Hyper-negative emotional states and hyperalgesia are both consequences of repeated alcohol use [46] and may contribute to an increase in alcohol use as a compensatory mechanism [47]. Among heavy drinkers, the negative emotional components of pain (i.e., pain catastrophizing) can enhance alcohol craving more than physical pain [48].

The emotional pain caused by the disruption or loss of social attachments also plays an important role in suicidality. In particular, suicidal ideation shares neurobiological and psychological features with separation distress-the innate, emotionally painful, dysphoric response of animals and humans to social separation or rejection [49, 50]. Converging evidence from preclinical and clinical studies supports the link between suicidal ideation and separation distress. Opioids reduce separation distress behaviors in non-human mammals [51-53] and have recently shown promise for the treatment of suicidality $[54,55]$. Suicidal acts are most common after interpersonal losses or rejections [56], and patients with borderline personality disorder are particularly susceptible to social rejection and often become suicidal after interpersonal rejections [57, 58].

\section{An Affective Neuroscience Model Linking Pain, Suicidal Ideation, and Depression}

Research in the field of affective neuroscience suggests that separation distress represents one of the ancestral primaryprocess emotional systems (referred to as PANIC/GRIEF) [49, 50, 59, 60]. Importantly, the PANIC/GRIEF system probably evolved from general pain mechanisms [59], and studies have found a link between separation distress and physical pain. 


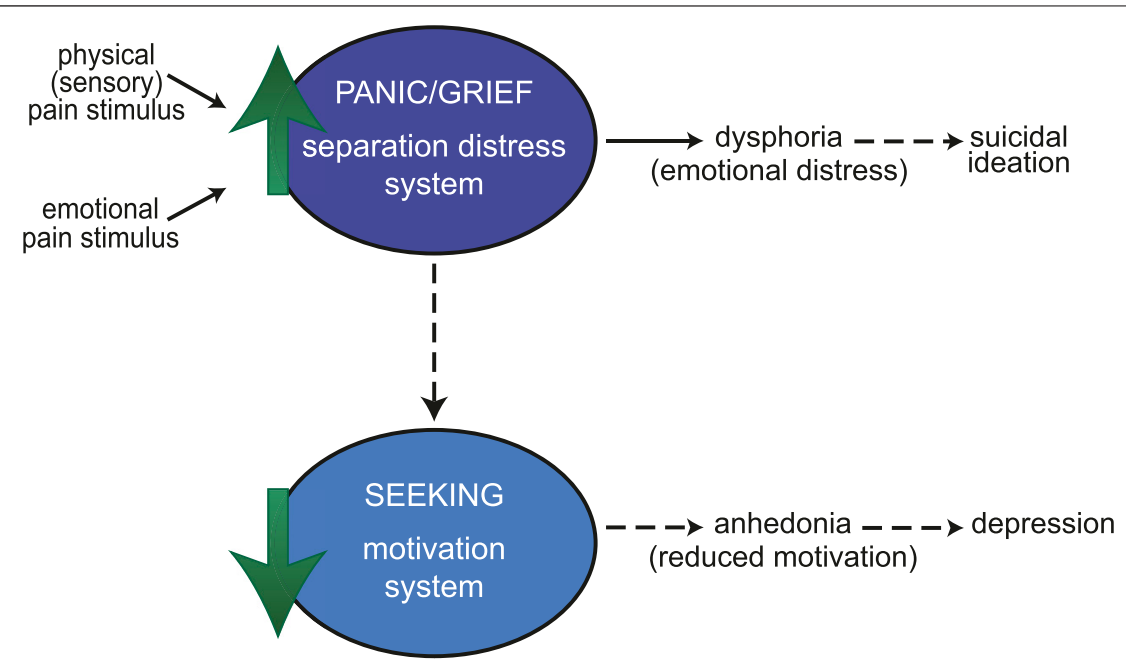

FIGURE 1 | An affective neuroscience model linking pain, suicidal ideation, and depression. Both physical (sensory) pain (such as injury) and emotional pain (such as interpersonal rejection) stimuli can act on the PANIC/GRIEF (separation distress) system. An increase in activity in this system produces dysphoria (emotional distress). Sustained activation of the PANIC/GRIEF system (dotted lines) could lead to suicidal ideation and a reduction in downstream activity of the SEEKING (motivation) system. Reduced motivation (anhedonia) may then result in loss of interest in activities characteristic of depression. This model suggests that suicidal ideation would often be comorbid with depression but could also occur independently of a disruption in reward processing.

Maternal separation in mouse neonates is capable of altering nociceptive behavior in adulthood [61, 62]. In humans, early life adversity in the form of both physical and psychological trauma (including familial separation) is associated with an increased risk of chronic pain in later life [63]. Studies show that parental bonding in adolescents is significantly associated with adolescent chronic pain and depression, where low maternal care contributes to increased pain via heightened depressive symptoms [64].

The neuroanatomy of the PANIC/GRIEF system overlaps with the brain's system for processing physical pain [65], suggesting that both physically painful (e.g., injury) and emotionally painful (e.g., interpersonal rejection) stimuli may engage this shared neurocircuitry to produce distress and dysphoria (emotional pain), with separation distress representing a particular subtype of emotional pain. The PANIC/GRIEF system also represents a potential substrate linking emotional pain/distress with suicidal ideation. The similarities between suicidal ideation and separation distress discussed above suggest that suicidal ideation may result from increased activity in the brain's PANIC/GRIEF network, whether initiated by social loss or physical injury. Thus, chronic pain patients may be particularly susceptible to suicidal ideation due to persistent activation of this system by painful sensory stimuli.

Sustained activation of the PANIC/GRIEF system can also lead to reduced activity in the brain reward SEEKING system (the system primarily responsible for motivation and arousal, particularly the mesolimbic dopamine pathway), perhaps as a means to protect against sustained emotional pain by reducing the overall arousal of emotions $[49,50,59,66]$. Underactivity in the SEEKING system causes blunted reward processing, leading to an amotivational state characterized by the diminished experience of positive feelings (anhedonia). Thus, down- regulation of the SEEKING system in response to sustained emotional pain (dysphoria) may be one underlying cause of the anhedonia and blunted affect that is characteristic of depression.

This two-stage model then suggests that the anhedonia of depression may reflect, in part, an emotional shutdown that follows the behavioral agitation of separation distress or other emotional pain, with these behavioral states correlating with underactivity of the SEEKING network and overactivity of the separation distress PANIC/GRIEF network, respectively. Of course, depression is a complex disorder that likely has multiple etiologies involving changes in many neural substrates. However, this model suggests one possible framework for understanding the relationship between suicidal ideation and depression. Sustained activation of the PANIC/GRIEF network may produce both a state of dysphoria that leads to suicidal ideation as well as, indirectly, a reduction in motivation (anhedonia) through subsequent downregulation of the reward SEEKING system (Figure 1). In this way, suicidal ideation would often be comorbid with depression but could be the result of dysregulation of the PANIC/GRIEF circuitry independent of a disruption in reward processing. In support of this hypothesis, patients with borderline personality disorder, but not comorbid depression, typically experience brief durations of suicidality as a result of interpersonal stresses. In contrast, patients with comorbid borderline personality disorder and depression display more persistent symptoms of depression and suicidality, which also include a loss of interest in ordinarily pleasurable activities (anhedonia) [18].

Ultimately, painful experiences (whether the emotional pain of social rejection or the physical/sensory pain characteristic of chronic pain conditions) likely engage shared brain systems 


\section{Affective (emotional) pain circuitry}
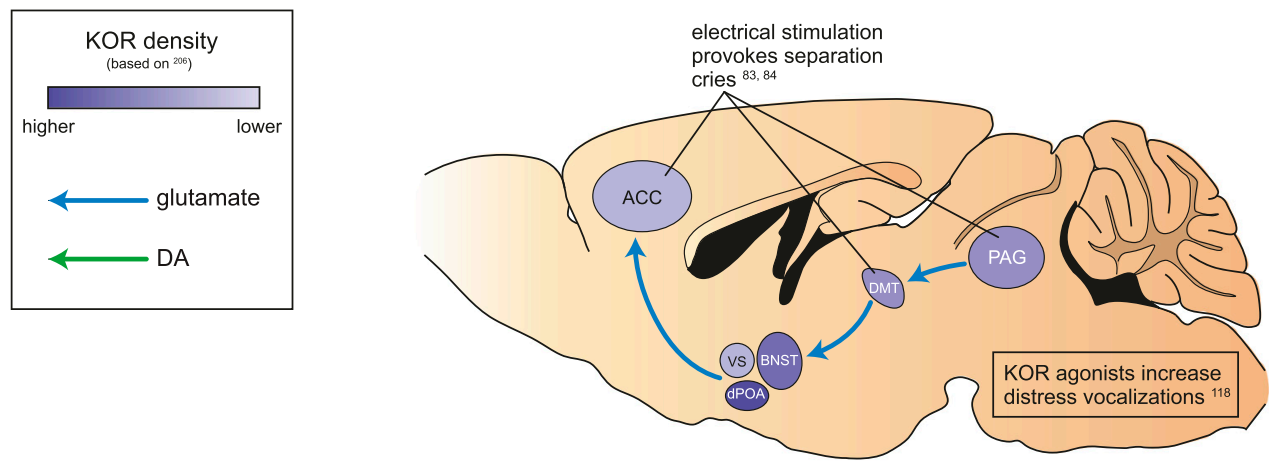

\section{Motivation and reward circuitry}

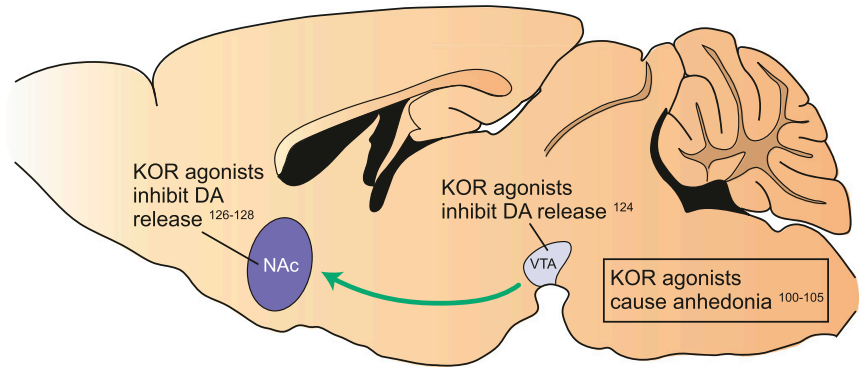

FIGURE 2 | Neurocircuitry and kappa opioid signaling involved in affective (emotional) pain and motivation and reward. Schematic of brain areas implicated in affective (emotional) pain, particularly separation distress (top), and motivation and reward (bottom) in rodents. Both circuits are altered by activity at KOR (present to varying degrees in all relevant brain regions). KOR antagonism increases distress vocalizations, inhibits mesolimbic DA release, and causes associated dysphoria and anhedonia. anterior cingulate cortex, ACC; ventral septum, VS; dorsal preoptic area, dPOA; bed nucleus of the stria terminalis, BNST; dorsalmedial thalamus, DMT; periaqueductal gray, PAG; nucleus accumbens, NAc; ventral tegmental area, VTA.

which produce negative affective states (distress/ dysphoria-implicated in suicidal ideation) and may subsequently disrupt downstream reward processing (anhedonia-implicated in depression), leading to a complex relationship between pain, separation/social distress, and motivation [65, 67, 68]. The neurocircuitry and neurochemistry underlying each is discussed in more detail below.

\section{Neurocircuitry of Pain, Separation/Social Distress, and Motivation Acute and Chronic Pain}

Pain is a multidimensional experience comprised of sensory, cognitive, and emotional components. The sensory aspects of pain are relayed from peripheral nociceptors, which detect noxious sensory stimuli, along primary afferent neurons that have central terminals in the spinal cord [69]. The second order neurons in the spinal cord ascend to various brain structures including the nucleus of the solitary tract, the medial brain stem reticular formation, the caudal ventrolateral medulla, the lateral parabrachial nucleus, the midbrain periaqueductal gray, and the thalamus and the hypothalamus $[69,70]$. The classical pathways associated with ascending nociceptive information are the lateral and medial spinothalamic pathways, where the lateral is responsible for sharp, well-localized pain and the medial is for diffuse, poorly localized persistent pain. Sensory information such as pain intensity and location (discriminative aspects of pain) is then relayed along the lateral spinothalamic tract to the primary and secondary somatosensory cortices via the medial thalamic nuclei. A descending pain modulation system originating in the periaqueductal gray (PAG) also regulates pain signals at the level of the spinal cord before they are relayed to higher subcortical and cortical structures [71].

The emotional and motivational aspects of pain (e.g., subjective unpleasantness and salience) are carried to limbic structures such as the amygdala, hypothalamus, striatum, insula, and anterior cingulate cortex by the medial spinothalamic tract [72-74] (Figure 2). A key structure for encoding the affective component of pain is the parabrachial complex located in the pons, receiving dense inputs form lamina I nociceptive spinal neurons; a projection reportedly denser than the spinothalamic pathway $[75,76]$. The parabrachial complex projects to several regions involved in pain and affect including 
the PAG, rostroventral medulla, thalamus, amygdala and zona incerta, making it a key structure for the affective emotional perception of pain.

The anterior cingulate has also been shown to be a critical brain region for the modulation of the subjective affective experience of pain [73]. Patients who have had a portion of the anterior cingulate surgically removed report that painful stimuli are no longer bothersome, even though they are able to localize pain sensations [77]. These findings support the idea that the distressing affective experience of a physically painful stimulus can be separated from its sensory properties.

Emotional pain also activates brain regions associated with physical pain including the PAG, insula, and anterior cingulate [78]; similarly, physical pain also activates limbic structures including the nucleus accumbens, ventral tegmental area (VTA), amygdala, and habenula [79-81]. Thus, the sensory and emotional components of pain are processed within discreet but interacting brain structures.

While a painful event serves an adaptive function and provides salience to a harmful stimulus that can support escape and avoidance learning, chronic pain can become pathological (serving no useful purpose). Although, it was recently proposed that this type of pain perhaps serves to provide hypervigilance [82]. Chronic pain involves neuroplasticity in the circuitry underlying both the sensory and affective components of pain. Patients with chronic pain suffer from sensory disturbances including allodynia (pain caused by a previously nonpainful stimulus) and hyperalgesia (exaggerated pain response to a previously painful stimulus). However, the negative affective component of chronic pain is argued to be a greater factor in quality of life measures [40].

\section{Separation/Social Distress}

Much of the same neurocircuitry described above is also engaged by separation distress, suggesting that the emotional pain elicited by separation distress is a result of the activation of circuits underlying physical pain. Specifically, the separation distress circuitry starts in the PAG and ascends through the dorsomedial thalamus, terminating in various basal forebrain regions including the anterior cingulate cortex [50, 59, 65] (Figure 2). Localized electrical stimulation of the anterior cingulate, dorsomedial thalamus, and PAG provoke separation cries in mammals $[83,84]$. In humans, the experience of emotional distress induced by social rejection is associated with an increase in activity in the anterior cingulate cortex measured by fMRI [85]. Together, these studies suggest that psychological pain, particularly social rejection and intense loneliness, may share some of the same neural pathways that elaborate physical pain.

\section{Motivation}

Reward and motivation, while often considered opponent processes to pain, are also processed within many of the same brain structures, in particular the mesolimbic system, which includes the VTA and nucleus accumbens (Figure 2). In neuropathic pain animals, functional connectivity is altered within the limbic system (including the nucleus accumbens) as well as between the limbic and nociceptive systems (including the thalamus, primary sensory cortices, insula, and PAG) [86]. In human clinical pain cohorts, connectivity is altered between the mesolimbic system and cortical structures [87-89]. Given that the mesolimbic system is responsible for the modulation of motivated behaviors and reinforcement learning [90, 91], altered activity in this system likely contributes to the negative affective component of pain. Pain can also directly impair general reward processing, leading to an anhedonic state [42]. Dopamine is a critical neurotransmitter within the mesolimbic system, and dopamine signaling in the nucleus accumbens may modulate the salience of painful experiences. While acute pain activates dopaminergic transmission to the nucleus accumbens [81, 92], chronic pain produces the opposite effect [93-95].

Together, the circuitry underlying pain, separation distress, and motivation provides a neuroanatomical substrate for the transition from physical or emotional pain to suicidality and possibly depression. Activity in pain/nociceptive circuitry (including the anterior cingulate, dorsomedial thalamus, and PAG) is correlated with the distress PANIC/GRIEF system, while activity in the mesolimbic circuit, particularly dopamine transmission in the nucleus accumbens, is correlated with the SEEKING system [50, 60, 66]. Sustained activity in the pain circuitry can reduce activity in the motivational circuitry through modulation of mesolimbic dopamine signaling, such that the distress caused by prolonged pain (sensory or emotional) may ultimately lead to decreased processing of rewarding stimuli. These neural substrates are further linked through shared activation by the opioid system, discussed in more detail below.

\section{The Opioid System}

\section{Receptors and Endogenous Ligands}

The opioid system, which modulates pain, social distress, and reward circuitry, may be a promising target for the treatment of behavioral disorders caused by disruptions in this circuitry, including suicidal ideation. Opioid receptors belong to the G-protein coupled receptor family and are divided into four families: the mu (MOR), delta (DOR), kappa (KOR) and nociceptin (NOR). These receptors are activated by four classes of endogenous opioid peptides, beta-endorphin, dynorphin, enkephalin and nociceptin. MORs have a high affinity for beta-endorphin and enkephalins, but low affinity for dynorphin. Conversely, dynorphin primarily acts through the KOR. Here we focus on the role of the MOR and, particularly, the KOR, as both have been implicated in the mediation of suicidal ideation by opioid drugs.

Opioid receptors are distributed throughout the central and peripheral nervous system and are present in many of the major structures involved in the pain circuitry, including the peripheral nociceptors, spinal cord, PAG, thalamus, anterior cingulate cortex, and other limbic regions [96]. The MOR is widely distributed throughout the brainstem, midbrain, and forebrain structures, and mediates the analgesic effects of most clinically available opioid medications, such as morphine [97]. KORs are located throughout the neuroaxis as well, and their localization in the spinal cord and brain stem can produce analgesia through the direct inhibition of pain pathways [98, 99]. 
While KOR and MOR expression widely overlaps throughout the brain, their activation produces opposing effects on mood [100]. Activation of KORs primarily produces negative emotions and dysphoria [101, 102], including depressive-like and psychotomimetic effects in humans [103-105] and rodents [100, 106-109]. In contrast, activation of the MOR is reinforcing and associated with positive hedonic experiences, Thus, in general, KOR activity is involved in an anti-reward system opposing rewarding MOR activity [110].

\section{Involvement in Pain, Separation/Social Distress, and Reward/Motivation}

Opioids and their receptors can modulate both the sensory and emotional (bothersome) components of pain. For example, when injected into the dorsomedial thalamus (a key region for processing both the sensory and affective components of pain), the MOR agonist DAGO elevated rats' sensory pain thresholds and induced a positive affective state, while the KOR agonist U50,488 reduced rats' pain thresholds and induced a negative affective state [111]. However, studies have shown sex differences with respect to the functioning of the MOR and KOR systems, particularly with respect to pain and addiction. Several comprehensive reviews are available [112-114].

In addition to their role in the sensory/affective components of pain, it is hypothesized that opioids constitute a major neurochemical underpinning of social bonding and isolation distress $[115,116]$. For example, opioid peptides are decreased in the midbrain of rat pups following social isolation [117], and endogenous opioid peptides acting at MORs have been shown in animal models to alleviate distress behaviors following social separation [115]. The MOR agonist morphine decreases distress vocalizations in rat pups isolated from their mother $[118,119]$, while the KOR agonist U50,488 increases isolationinduced ultrasonic vocalization [118]. Thus, it appears that dynorphins are responsible for mediating negative affect within the neurocircuitry underlying social distress, similar to their role in the modulation of physical pain (Figure 2).

High expression levels of KOR have been also detected in brain areas responsible for reward and motivation, including the VTA and nucleus accumbens [120, 121] (Figure 2). The ability of KOR agonists to negatively modulate mesolimbic dopamine has significant implications for motivated behavior. Since reduced nucleus accumbens dopamine signaling is associated with a loss of motivation, KOR modulation of dopamine circuitry may link the acute distress of physical or emotional pain with the subsequent onset of negative motivational states and affect.

Studies in rat brain slices show that KOR agonists (U69,593) are capable of suppressing mesolimbic dopamine release via receptors expressed on dopamine neuronal terminals as well as neuronal cell bodies [122-125], which may contribute to the dysphoric effects of KOR activation. KOR agonists (including U50,488, spiradoline, U69,593) also inhibit dopamine signaling when applied directly into the nucleus accumbens of rats, as measured by microdialysis in intact animals [126, 127] or by superfused brain slices [128]; however, changes in dopamine signaling in the nucleus accumbens did not correlate with
KOR agonist (U50,488) induced conditioned place aversion (CPA) in mice [129]. Furthermore, morphine-evoked increases in extracellular dopamine within the nucleus accumbens were blocked by the administration of a KOR agonist (U50,488) into this brain region in mice [130]. Finally, the expression of KORmediated aversion (U69,593-induced CPA) requires the activity of medium spiny neurons expressing dopamine receptors within the nucleus accumbens of rats [131] and mice [132].

Activation of KORs also contributes to the dopamine hypofunction observed in chronic pain states. Given that hypo-dopaminergic states contribute to chronic pain [133, 134] and mood disorders comorbid with chronic pain [135], KOR antagonism to recover dopamine may hold promise as a novel therapeutic for treating chronic pain and associated mood disorders. Indeed, reduced motivation for food (sucrose) reward induced by inflammatory pain was recovered by KOR antagonism (with norBNI) or silencing of dynorphin neurons within the ventral striatum of rats [136]. A comprehensive review of KOR function in chronic pain and its relationship with drugseeking behavior is available [137].

The role of KORs in dysfunctions of reward and motivation is particularly well-characterized with respect to AUD. KORmediated reductions in dopamine release in the nucleus accumbens have been hypothesized to mediate negative emotional states associated with alcohol withdrawal, particularly pain associated with acute alcohol withdrawal [138]. At the preclinical level, alcohol-preferring rats show increased dynorphin mRNA expression in the central amygdala and hypothalamus compared to non-preferring rats after voluntary drinking [139]. The KOR antagonist norBNI also attenuates withdrawal-related anxiety-like behaviors in alcoholdependent mice [140]. In addition to alleviating alcohol-induced negative affective states, pharmacotherapies with KOR antagonist properties, including buprenorphine, reduce binge-like alcohol drinking [141, 142], alcohol self-administration [143, 144], and block escalation of compulsive-like drinking after dependence induction [145, 146] and stress exposure [147] in rodent.

The ability of opioids to modulate both sensory/affective pain circuits as well as reward/motivation circuits suggests these compounds have the capability to counteract multiple features of suicidality and depression. Opioids are able to produce dopamine-independent positive affective states through their influence on pain and social distress circuits, including areas such as the anterior cingulate cortex, PAG, and dorsomedial thalamus. Opioids can also counteract negative affective states by promoting increased motivational drive through their downstream influence on dopaminergic reward circuits, especially in the nucleus accumbens. Thus, since opioids can restore deficits in both pain and reward circuits, they may be particularly useful in treating suicidal ideation, as they would be able to blunt suicidality whether it was caused primarily by a disruption in dopaminergic motivational circuity or a disruption in non-dopaminergic pain/social distress circuits. Other treatments which primarily target reduced motivation (anhedonia) may not be effective in treating the subset of individuals experiencing suicidal ideation without a concomitant reduction in motivation (i.e., patients with or without comorbid depression). 
Buprenorphine Attenuates Suicidal Ideation Given the above understanding of the opioid system, there has been a renewed interest in the use of opioid analgesics, particularly buprenorphine, for the treatment of suicidality. A retrospective 24-months study reported buprenorphine had the lowest incidence of suicide intent and deaths compared to other opioid analgesics [148]. Buprenorphine has demonstrated rapid antidepressant effects in humans [149-152], including those with treatment-resistant depression, and has shown particular promise in reducing suicidal ideation [153].

\section{Buprenorphine Mechanism}

Buprenorphine is an analgesic derived from oripavine that acts as a partial MOR agonist and KOR antagonist, as well as an antagonist at the DOR and an agonist at the NOR [154]. Buprenorphine has similar affinities for the MOR and KOR, but a 10-fold lower affinity for the DOR [154]. For the purposes of this review, we have largely limited our discussion to the MOR agonist and KOR antagonist effects as these are wellcharacterized, although note that some work has shown that buprenorphine may have partial agonist activity at KORs [155-157]. Importantly, due to its partial MOR agonist properties, buprenorphine has a lower overdose risk compared to full MOR agonists such as morphine [158].

\section{Clinical Studies Demonstrating the Effects of Buprenorphine on Behavior}

The potential anti-suicidal effects of buprenorphine were first described in a case report of a 61-year-old woman suffering from treatment-resistant depression, chronic back pain, severe opioid use disorder, and ongoing suicidal ideation [159]. While treatment with buprenorphine (16 mg/4 mg buprenorphine/ naloxone) was prescribed to treat the patient's opioid use disorder, she reported that her suicidal ideation completely disappeared after 1 week of treatment, and suicidal ideation remained absent up to 3 months after the initial treatment. In another case report, a patient with cannabis-induced psychotic disorder and opioid depressive disorder with severe suicidal thoughts was treated successfully with a single high dose (96 mg) of buprenorphine [160]. Another case report showed that buprenorphine/naloxone $(8 \mathrm{mg} / 2 \mathrm{mg}$ ) was effective in reducing pain and suicidal ideation in a 39 -year-old male with a history of bipolar disorder, multiple suicide attempts, and polysubstance abuse [161]. Chart reviews of suicidal adult depressed patients with comorbid chronic pain and opioid use disorder who received offlabel buprenorphine also found some support for the anti-suicidal properties of buprenorphine [162]. The presence of chronic pain, depression, and substance use in these case reports and studies suggests that buprenorphine may effectively mitigate suicidal ideation by targeting multiple overlapping neurocircuits, which underlie these often-comorbid disorders.

Based on these case reports and anecdotal findings, clinical trials have begun to explore the anti-suicidal potential of buprenorphine. A multisite randomized double-blind placebo-controlled trial of ultra-low-dose (initial dosage, $0.1 \mathrm{mg}$ once or twice daily; mean final dosage, $0.44 \mathrm{mg}$ /day) buprenorphine found that severely suicidal patients showed a reduction in Beck Scale for Suicidal Ideation (BSSI) scores after 2 and 4 weeks of treatment compared to patients that received placebo [54]. Another randomized clinical trial tested the efficacy of one of three single high doses of buprenorphine $(32,64,96 \mathrm{mg})$ in suicidal opioid-dependent patients [163]. The researchers found that BSSI scores were significantly reduced in patients across all three buprenorphine doses. While these findings suggest that buprenorphine has particular promise as an anti-suicide treatment option, more research is needed to determine the conditions under which buprenorphine treatment is most effective and tolerable, including whether low or high doses are more successful (the wide range of effective doses in these clinical trials - from 0.44 to $96 \mathrm{mg}$ - is interesting and will be an important area for future studies) and whether treatment is affected by comorbidities including substance use disorder or chronic pain.

Other studies have examined the effects of buprenorphine in combination with other drugs. A randomized double-blind placebocontrolled trial in adults with treatment-resistant depression showed that treatment with $2 \mathrm{mg} / 2 \mathrm{mg}$ buprenorphine/samidorphan significantly improved scores on multiple depression measures compared to placebo controls [164]. Antidepressant activity was also demonstrated in another study using a 1:1 ratio of buprenorphine:samidorphan [165]. Samidorphan is a MOR antagonist, thus this combined treatment leaves the KOR antagonist activity of buprenorphine intact while blocking the MOR agonist activity of buprenorphine. Blocking the subjective and objective MOR effects likely mitigates the potential addictive properties of buprenorphine in opioid-naïve individuals. While these studies did not directly measure suicidal ideation independent of depression, they provide important insight into the potential mechanisms of buprenorphine's behavioral effects. In both cases, the effects of buprenorphine were not blocked by a MOR antagonist, suggesting that activity at this receptor may not be required for the anti-suicidal effects of buprenorphine.

\section{Preclinical Studies Demonstrating the Effects of Buprenorphine on Behavior}

In addition to the clinical findings described above, pre-clinical studies also support the potential anti-suicidal treatment effects of buprenorphine. While no behavioral assays for suicidal ideation exist for rodents, several behavioral assays have been validated to screen for depressive-like behaviors, including the forced swim test and the novelty-induced hypophagia test. The forced swim test is considered a measurement of behavioral despair [166] and is one of the gold-standard screens for depressive behavior as it is reliably reversed by antidepressants [167]. The novelty-induced hypophagia test is a conflict-based behavioral task that assesses the impact of an environmental stressor on animals' conditioned approach toward a palatable food reward, with longer approach latencies indicating greater depressive or anxious behavior [168]. Treatment with antidepressants or benzodiazepines reduces approach latencies in the novelty-induced hypophagia test [168-170].

In mice, administration of buprenorphine produced significant reductions in forced swim test immobility (at doses ranging from $0.065-2 \mathrm{mg} / \mathrm{kg}$ ) and reduced approach latencies in 
TABLE 1 | Review of evidence supporting the role of KOR in the anti-suicidal effects of buprenorphine. Letters indicate experimental model: $(m)$, mouse; $(r)$, rat; $(h)$, human.

\begin{tabular}{lrr}
$\begin{array}{l}\text { Opioid receptor } \\
\text { subtype }\end{array}$ & $\begin{array}{r}\text { Experimental } \\
\text { manipulation }\end{array}$ & Behavioral effect \\
\hline $\mathrm{KOR}$ & $\uparrow,($ Up-regulated $)$ & + (pro-depressant)
\end{tabular}

$\mathbf{U 6 9 , 5 9 3}$ exacerbated pain-depressed ICSS $(r)$ [106], elevated ICSS threshold $(r)$ [108], depressed nesting behavior $(m)$ [191], and produced place aversion $(m, r)[131,132,181]$

- Salvinorin A increased immobility on forced swim (r) [107], elevated ICSS threshold $(r)$ [107], and produced psychomimetic effects $(r, h)[195,196]$

- Cyclazocine produced dysphoria \& psychomimetic effects (h) [197]

- U50,488 produced conditioned place aversion (CPA) $(m)[109,129]$ and CPA was exacerbated in chronic pain animals $(m)$ [182]

- Nalfurafine did not alter pain-depressed ICSS $(r)$ [180]

0 (no effect)

$\downarrow$,(Down-regulated) -(anti-depressant)

- Salvinorin A reduced anhedonia caused by chronic mild stress (CMS) (r) [198]

- norBNI did not alter pain-depressed ICSS $(r)$ [106] or approach latency in the NIH test $(m)$ [175]

- JDTic did not alter pain-related depression of nesting behavior (m) [191]

- norBNI reduced immobility on forced $\operatorname{swim}(m, r)[109,171,179,183-187]$, reduced aversive behaviors produced by inescapable footshock $(m)$ [109], reduced expression of learned helplessness (r) [199], prevented CPP to gabapentin in a spinal nerve ligation (SNL) injury (r) [200], reduced social impairment produced by heroin abstinence $(m)$ [201], and attenuated cocaine-withdrawal induced increase in ICSS threshold $(r)$ [186]

- JDTic reduced immobility on forced swim (r) [187], blocked depression of nesting behavior by KOR agonist $(m)$ [191], and reduced footshock-induced reinstatement of cocaine seeking (r) [187]

- $\boldsymbol{M C L - 1 4 4 B}$ reduced immobility on forced swim $(m)$ [188]

- KOR knockout mice had disrupted BPN-induced reduction in forced swim immobility (m) [179] and reduced social aversion following heroin abstinence $(m)$ [202]

the novel environment of the novelty-induced hypophagia test (at a dose of $0.25 \mathrm{mg} / \mathrm{kg}$ ) [171]. In Wistar Kyoto (WKY) rats, a strain which has an exaggerated depressive phenotype and is resistant to certain antidepressants, buprenorphine $(2.25 \mathrm{mg} / \mathrm{kg})$ significantly reduced immobility in the forced swim test [172]. This effect was specific to the WKY strain, suggesting that buprenorphine may be more effective in individuals with certain treatment-resistant depressions. In general, the doses which produced behavioral effects in these preclinical studies were lower than those used in clinical trials; however, one trial showed that an ultra-low dose of buprenorphine $(0.44 \mathrm{mg} / \mathrm{day}$, comparable to the preclinical doses) significantly reduced suicidal ideation [54].

\section{The Contribution of Kappa Versus Mu Activity in the Anti-Suicidal Effects of Buprenorphine}

A better understanding of the specific pharmacological underpinnings of the anti-suicidal and anti-depressive effects of buprenorphine would be valuable as it could inform the development of even more targeted therapeutics which might avoid side effects, including abuse potential. As discussed previously, buprenorphine is both a partial agonist at the MOR and an antagonist at the KOR, but which receptor type is primarily responsible for the anti-suicidal and anti-depressive effects of the drug is uncertain. A review of preclinical studies can help to shed light on this question. In general, the data are conflicting, and both MOR partial agonist and KOR antagonist activity likely play a role in the anti-suicidal effects of buprenorphine. However, the data supporting the importance of KOR antagonism appear slightly more consistent (discussed in more detail below).

\section{Studies With Buprenorphine}

Studies combining buprenorphine with opioid antagonists suggest that the MOR is not necessary for the behavioral effects of buprenorphine. In mice, the anti-depressive effects of buprenorphine described above (reduction in forced swim test immobility and reduced approach latency in the novelty-induced hypophagia test) were maintained when buprenorphine $(1 \mathrm{mg} / \mathrm{kg})$ was co-administered with the opioid antagonist naltrexone $(1 \mathrm{mg} / \mathrm{kg})$, suggesting that activation of MORs is not necessary for the expression of buprenorphine's anti-depressive effects [173]. Co-administration of buprenorphine $(0.1 \mathrm{mg} / \mathrm{kg})$ with the MOR antagonist samidorphan $(0.3 \mathrm{mg} / \mathrm{kg})$ in Wistar Kyoto rats did not alter the drug's efficacy in the forced swim test [174], again suggesting that activation of MOR is not necessary for the anti-depressive effects of buprenorphine.

The use of selective knockout mice provides evidence that the behavioral effects of buprenorphine may be mediated by both MOR and KOR. In mice with genetic deletion of the MOR $\left(\mathrm{Oprml}^{-1-}\right)$ or KOR $\left(O p r k 1^{-l-}\right)$, buprenorphine $(0.25 \mathrm{mg} / \mathrm{kg})$-induced decreases in latency in the novelty-induced hypophagia test were blocked in Oprm1 $^{-/-}$but not Oprk1 ${ }^{-/-}$mice [175], suggesting that buprenorphine's activity at MOR, but not KOR, is required for its anti-depressive effects. Consistent with this idea, a mouse model of the A118G polymorphism (associated with less opioid receptor expression and lower signaling efficiency) in the MOR gene (OPRM1) also disrupted the effects of buprenorphine on this behavior [176]. These data are further supported by human studies which have found that the A118G polymorphism was associated with treatment onset suicidal ideation [177] and more severe depression following a recent targeted rejection major life event [178].

In contrast, knockout of the KOR in mice blocked buprenorphine's reduction of immobility in the forced swim 
TABLE 2 | Review of evidence supporting the role of MOR in the anti-suicidal effects of buprenorphine. Letters indicate experimental model: $(m)$, mouse; $(r)$, rat; $(h)$, human.

\begin{tabular}{|c|c|c|c|}
\hline $\begin{array}{l}\text { Opioid receptor } \\
\text { subtype }\end{array}$ & $\begin{array}{l}\text { Experimental } \\
\text { manipulation }\end{array}$ & $\begin{array}{c}\text { Behavioral } \\
\text { effect }\end{array}$ & \\
\hline \multirow[t]{12}{*}{ MOR } & $\uparrow$ & + & \\
\hline & & 0 & $\begin{array}{l}\text { - Morphine did not alter behavior on forced swim }(m) \text { [171], approach latency in NIH test }(m) \\
\text { [175], nor the depression of nesting behavior by a KOR agonist }(m) \text { [191] }\end{array}$ \\
\hline & & - & $\begin{array}{l}\text { - Morphine reduced learned helplessness }(r) \text { [189], decreased immobility on the tail } \\
\text { suspension test }(m) \text { [190], blocked pain-depressed ICSS }(r) \text { [106], and alleviated pain-related } \\
\text { depression of nesting behavior }(m) \text { [191] }\end{array}$ \\
\hline & & & - Codeine decreased immobility on tail suspension test $(m)[190,203]$ \\
\hline & & & $\begin{array}{l}\text { - Methadone reduced learned helplessness }(r)[204] \text { and decreased immobility on tail } \\
\text { suspension test }(m) \text { [190] }\end{array}$ \\
\hline & & & $\begin{array}{l}\text { - Tramadol reduced learned helplessness }(r) \text { [204] and decreased immobility on tail } \\
\text { suspension test }(m) \text { [190] }\end{array}$ \\
\hline & & & - Opiorphin reduced immobility in forced swim $(m)$ [205] \\
\hline & $\downarrow$ & + & $\begin{array}{l}\text { - MOR knockout mice had disrupted BPN-induced reduction in latency in the NIH test }(m) \\
\text { [175] }\end{array}$ \\
\hline & & & $\begin{array}{l}\text { - Mouse model of the OPRM1 A118G polymorphism had disrupted BPN-induced } \\
\text { reduction in latency in NIH test }(m)[176]\end{array}$ \\
\hline & & & $\begin{array}{l}\text { - OPRM1 A118G polymorphism associated with suicidal ideation (h) [177] and more severe } \\
\text { depression (h) [178] }\end{array}$ \\
\hline & & 0 & \\
\hline & & - & $\begin{array}{l}\text { - Cyprodime reduced approach latency in NIH test }(m) \text { [175] } \\
\text { - } \text { MOR knockout mice had reduced immobility in forced swim }(m) \text { [192] and showed } \\
\text { reduced anxiogenic and depressive-like responses }(m) \text { [193] }\end{array}$ \\
\hline
\end{tabular}

test while knockout of the MOR did not disrupt the behavioral effects of buprenorphine $(0.25-0.5 \mathrm{mg} / \mathrm{kg})$ [179], suggesting that buprenorphine's activity at KOR, but not MOR, is required for its anti-depressive effects. Together, these studies indicate that the role of different opioid receptor types in buprenorphine's antisuicidal and anti-depressive effects are likely mediated by multiple factors including behavioral assay, genetic background, and drug dose.

\section{Studies With Other Drugs That Have Kappa and Mu Activity}

We can also examine the behavioral effects of other KOR and MOR drugs to further explore the potential role of opioid receptor subtype in the behavioral effects of buprenorphine. Since buprenorphine is an antagonist at the KOR, if activity at this receptor is primarily responsible for the anti-suicidal effects of buprenorphine, we would expect manipulations that increase activity at KOR to be pro-depressive while manipulations that decrease activity at KOR to be anti-depressive (Table 1, dark blue cells). Conversely, buprenorphine is a partial agonist of the MOR, so if activity at this receptor is primarily responsible for the antisuicidal effects of buprenorphine, we would expect manipulations that increase activity at MOR to be anti-depressive while manipulations that decrease activity at MOR to be prodepressive (Table 2, yellow cells).

\section{Kappa Agonists}

In general, KOR agonists produce behaviors indicative of depressed mood or dysphoria. An increase in intra-cranial self-stimulation (ICSS) threshold is a commonly used measure of dysphoria in rodents, and the KOR agonists
U69,593 ${ }^{108}$ and salvinorin A [107] have been shown to increase ICSS thresholds in rats; however, another KOR agonist nalfurafine had no effect on this behavior [180]. Note that this effect could be due to the sedative effects of U69,593; however, U69,593 also produced a conditioned place aversion (CPA) in mice [132] and rats [131, 181], an effect consistent with the induction of a negative affective state. The KOR agonist U50,488 also induced a CPA [109], a behavior that we recently showed was exacerbated in chronic pain animals [182]. Given that the vast majority of preclinical studies find that KOR agonism produces depressive-like behaviors (see Table 1), there is strong support for the hypothesis that decreased activity at this receptor underlies the anti-depressant and anti-suicidal properties of buprenorphine.

\section{Kappa Antagonists}

Conversely, KOR antagonists tend to have the opposite effect, producing antidepressant effects in multiple behavioral assays. In particular, a number of studies indicate that KOR antagonists, including norBNI [109, 171, 179, 183-187], JDTic [187], and MCL-144B [188], reduce immobility on the forced swim test in rats and mice. Numerous studies support the anti-depressive effects of KOR anatgonists, particularly norBNI and JDTic (see Table 1), further supporting the role of KOR antagonism in the behavioral effects of buprenorphine.

\section{Mu Agonists}

MOR agonists have been shown to produce antidepressant-like effects, though their efficacy depends on the particular behavioral assay employed (see Table 2). For example, the MOR agonist morphine produced antidepressant-like effects in the learned helplessness model [189] and the tail suspension test [190], but 
did not have an effect in the forced swim test [171] or in the noveltyinduced hypophagia test [175]. Morphine was effective at recovering pain-reduced behaviors including a pain-induced reduction in ICSS responding (increased ICSS threshold) [106] and pain-reduced nesting behavior [191] (although it did not block reduced nesting behavior caused by the KOR agonist U69,593) [191].

\section{Mu Antagonists}

The effects of MOR antagonism on depressive-like behaviors are less conclusive (see Table 2). The selective MOR antagonist cyprodime reduced approach latencies in the novelty induced hypophagia test in mice [175], an antidepressant-like effect which is inconsistent with the hypothesis that a decrease in activity at the MOR should promote depressive behaviors. Furthermore, MOR knockout mice have shown reduced immobility in the forced swim test [192] and reduced anxiogenic and depressive-like responses [193]. These data suggest that activity specifically at the MOR is less likely to underlie the anti-suicidal and antidepressant properties of buprenorphine, since either increases or decreases in activity at the MOR are capable of producing antidepressant behaviors.

Overall, it appears that the evidence for MOR activation underlying buprenorphine's anti-suicidal effects is less convincing than the evidence for KOR antagonism underlying these effects. This conclusion is based primarily on: 1) the inability of MOR antagonists to block the anti-depressive and anti-suicidal effects of buprenorphine in humans $[159,164,165]$ and 2) rodents $[173,174]$, and 3$)$ the anti-depressive effects of some manipulations which decrease MOR activity [175, 192, 193].

\section{CONCLUSION}

This review has summarized the human and preclinical studies that support further investigation of the potential of buprenorphine treatment for reducing suicidal ideation. The unique pharmacology of buprenorphine that includes partial MOR agonism and KOR antagonism likely contributes to its

\section{REFERENCES}

1. Hawton K, and van Heeringen K Suicide. The Lancet 373, 1372-81. (2009). doi:10.1016/s0140-6736(09)60372-x

2. National Institutes of Health, N. I. of M. H. U. S. D. of H. HS Suicide. Available at: https://www.nimh.nih.gov/health/statistics/suicide.shtml.

3. The Surgeon General's Call to Action to Implement the National Strategy for Suicide Prevention. Available at: https://www.hhs.gov/sites/default/files/sprccall-to-action.pdf (2021).

4. Asmundson GJG, and Katz J. Understanding the Co-occurrence of Anxiety Disorders and Chronic Pain: State-of-the-art. Depress Anxiety 26, 888-901. (2009). doi:10.1002/da.20600

5. Elman I, Borsook D, and Volkow ND. Pain and Suicidality: Insights from Reward and Addiction Neuroscience. Prog Neurobiol 109, 1-27. (2013). doi:10.1016/j.pneurobio.2013.06.003

6. Parra-Uribe I, Blasco-Fontecilla H, Garcia-Parés G, Martínez-Naval L, Valero-Coppin $\mathrm{O}$, Cebrià-Meca A, et al. Risk of Re-attempts and Suicide Death after a Suicide Attempt: A Survival Analysis. BMC Psychiatry 17, 163 (2017). doi:10.1186/s12888-017-1317-z

7. Niederkrotenthaler T, Gunnell D, Arensman E, Pirkis J, Appleby L, Hawton K, et al. Suicide Research, Prevention, and COVID-19. Crisis vol. 41, 321-30. (2020). doi:10.1027/0227-5910/a000731 potential therapeutic effects, where there is strong support for KOR antagonism in alleviating anhedonia and depression. Given the high rate of suicidal ideation and death by suicide in both chronic pain and substance use disorder patients, further research should focus on the development of novel KOR antagonists that do not possess the potential for abuse. Buprenorphine is a potent opioid analgesic (more potent than morphine), and while it is an effective treatment for opioid use disorder, it can be used illicitly where there is evidence of misuse, abuse and diversion [194]. Thus, it is important to understand if drugs which combine buprenorphine with a MOR antagonist (such as naloxone; including drugs like Suboxone ${ }^{\circledR}$ ) have anti-suicide properties similar to buprenorphine itself. Overall, buprenorphine and KOR drugs have great potential for the treatment of suicidal behavior and future study may lead to safer and more effective pharmacotherapies.

\section{AUTHOR CONTRIBUTIONS}

All authors contributed to various aspects of the writing of the paper. CoMC edited and finalized the paper.

\section{FUNDING}

The Shirley Hatos Foundation supported CaMC and CoMC. NIH Grant numbers R01DA041781 (CaMC), 1UG3TR003148-01 (CaMC) and 2P50 DA005010 (CaMC), and the Department of Defense Grant number W81XWH-15-1-0435 (CaMC).

\section{CONFLICT OF INTEREST}

The authors declare that the research was conducted in the absence of any commercial or financial relationships that could be construed as a potential conflict of interest.

8. Gunnell D, Appleby L, Arensman E, Hawton K, John A, Kapur N, et al. Suicide Risk and Prevention during the COVID-19 Pandemic. Lancet Psychiatry 7, 468-71. (2020). doi:10.1016/S2215-0366(20)30171-1

9. Czeisler MÉ, Lane RI, Petrosky E, Wiley JF, Christensen A, Njai R, et al. Mental Health, Substance Use, and Suicidal Ideation during the COVID-19 Pandemic - United States, June 24-30, 2020, MMWR Morb Mortal Wkly Rep 69, 1049-57. (2020). doi:10.15585/mmwr.mm6932a1

10. Pirkis J, John A, Shin S, DelPozo-Banos M, Arya V, Analuisa-Aguilar P, et al. Suicide Trends in the Early Months of the COVID-19 Pandemic: an Interrupted Time-Series Analysis of Preliminary Data from 21 Countries. The Lancet Psychiatry 8(7):579-88.(2021) doi:10.1016/S2215-0366(21)00091-2

11. Mann JJ, and Currier D in Suicide Prevention Insights from Neurobiology of Suicidal Behavior. in The Neurobiological Basis of Suicide (In: D Y., editor) (CRC Press/Taylor \& Francis, 2012).

12. Ballard ED, Ionescu DF, Vande Voort JL, Niciu MJ, Richards EM, Luckenbaugh DA, et al. Improvement in Suicidal Ideation after Ketamine Infusion: Relationship to Reductions in Depression and Anxiety. J Psychiatr Res 58, 161-6. (2014). doi:10.1016/j.jpsychires.2014.07.027

13. Bohnert KM, Ilgen MA, Louzon S, McCarthy JF, and Katz IR. Substance Use Disorders and the Risk of Suicide Mortality Among Men and Women in the US Veterans Health Administration. Addiction 112, 1193-201 (2017). doi:10.1111/add.13774 
14. Czeisler MÉ, Lane RI, Petrosky E, Wiley JF, Christensen A, Njai R, et al. Mental Health, Substance Use, and Suicidal Ideation during the COVID-19 Pandemic - United States, June 24-30, 2020. MMWR Morb Mortal Wkly Rep vol. 69, 1049, 57. (2020). doi:10.15585/mmwr.mm6932al

15. Wilcox HC, Conner KR, and Caine ED. Association of Alcohol and Drug Use Disorders and Completed Suicide: an Empirical Review of Cohort Studies. Drug Alcohol Depend 76 Suppl, S11, 9. (2004). doi:10.1016/ j.drugalcdep.2004.08.003

16. Oquendo MA, and Volkow ND. Suicide: A Silent Contributor to OpioidOverdose Deaths. N Engl J Med 378, 1567-9. (2018). doi:10.1056/ nejmp1801417

17. Abreu LN, Oquendo MA, Galfavy H, Burke A, Grunebaum MF, Sher L, et al. Are Comorbid Anxiety Disorders a Risk Factor for Suicide Attempts in Patients with Mood Disorders? A Two-Year Prospective Study. Eur Psychiatry 47, 19, 24., (2017). doi:10.1016/j.eurpsy.2017.09.005

18. Soloff PH, Lynch KG, Kelly TM, Malone KM, and Mann JJ. Characteristics of Suicide Attempts of Patients with Major Depressive Episode and Borderline Personality Disorder: a Comparative Study. Am J Psychiatry 157, 601-8. (2000). doi:10.1176/appi.ajp.157.4.601

19. Ertl A, Sheats KJ, Petrosky E, Betz CJ, Yuan K, and Fowler KA. Surveillance for Violent Deaths - National Violent Death Reporting System, 32 States, 2016, MMWR Surveill Summ. 68, 1-36. (2019). doi:10.15585/mmwr.ss.6809a1

20. Conner A, Azrael D, and Miller M. Suicide Case-Fatality Rates in the United States, 2007 to 2014. Ann Intern Med 171, 885-95. (2019). doi:10.7326/m19-1324

21. Darvishi N, Farhadi M, Haghtalab T, and Poorolajal J. Alcohol-related Risk of Suicidal Ideation, Suicide Attempt, and Completed Suicide: a Meta-Analysis. PloS one 10, e0126870 (2015). doi:10.1371/journal.pone.0126870

22. Cavanagh JTO, Carson AJ, Sharpe M, and Lawrie SM. Psychological Autopsy Studies of Suicide: a Systematic Review. Psychol Med 33, 395-405. (2003). doi:10.1017/s0033291702006943

23. Fishbain DA. The Association of Chronic Pain and Suicide. in Seminars in Clinical Neuropsychiatry vol. 4 221-7. (1999).

24. Ilgen MA, Zivin K, Austin KL, Bohnert AS, Czyz EK, Valenstein M, et al. Severe Pain Predicts Greater Likelihood of Subsequent Suicide. Suicide LifeThreatening Behav 40, 597-608. (2010). doi:10.1521/suli.2010.40.6.597

25. Ratcliffe GE, Enns MW, Belik S-L, and Sareen J. Chronic Pain Conditions and Suicidal Ideation and Suicide Attempts: an Epidemiologic Perspective. The Clin J pain 24, 204-10. (2008). doi:10.1097/ajp.0b013e31815ca2a3

26. Tang NKY, and Crane C. Suicidality in Chronic Pain: a Review of the Prevalence, Risk Factors and Psychological Links. Psychol Med 36, 575 (2006). doi:10.1017/s0033291705006859

27. Edwards RR, Smith MT, Kudel I, and Haythornthwaite J. Pain-related Catastrophizing as a Risk Factor for Suicidal Ideation in Chronic Pain. Pain 126, 272-9. (2006). doi:10.1016/j.pain.2006.07.004

28. Fisher BJ, Haythornthwaite JA, Heinberg LJ, Clark M, and Reed J. Suicidal Intent in Patients with Chronic Pain. Pain 89, 199-206. (2001). doi:10.1016/ s0304-3959(00)00363-8

29. Smith MT, Edwards RR, Robinson RC, and Dworkin RH. Suicidal Ideation, Plans, and Attempts in Chronic Pain Patients: Factors Associated with Increased Risk. Pain 111, 201-8. (2004). doi:10.1016/j.pain.2004.06.016

30. Blackburn-Munro G, and Blackburn-Munro RE. Chronic Pain, Chronic Stress and Depression: Coincidence or Consequence? J neuroendocrinology 13, 1009-23. (2001). doi:10.1046/j.0007-1331.2001.00727.x

31. Fishbain DA, Cutler R, Rosomoff HL, and Rosomoff RS. Chronic Pain-Associated Depression: Antecedent or Consequence of Chronic Pain? A Review. Clin J pain 13, 116-37. (1997). doi:10.1097/00002508-199706000-00006

32. Conejero I, Olié E, Calati R, Ducasse D, and Courtet P. Psychological Pain, Depression, and Suicide: Recent Evidences and Future Directions. Curr Psychiatry Rep 20, 33 (2018). doi:10.1007/s11920-018-0893-z

33. Meerwijk EL, and Weiss SJ. Tolerance for Psychological Pain and Capability for Suicide: Contributions to Suicidal Ideation and Behavior. Psychiatry Res 262, 203-8. (2018). doi:10.1016/j.psychres.2018.02.005

34. Calati R, Laglaoui Bakhiyi C, Artero S, Ilgen M, and Courtet P. The Impact of Physical Pain on Suicidal Thoughts and Behaviors: Meta-Analyses. J Psychiatr Res 71, 16-32. (2015). doi:10.1016/j.jpsychires.2015.09.004

35. Tang NKY, Beckwith P, and Ashworth P. Mental Defeat Is Associated with Suicide Intent in Patients with Chronic Pain. Clin J pain 32, 411-9. (2016). doi:10.1097/ajp.0000000000000276
36. Winsper C, and Tang NKY. Linkages between Insomnia and Suicidality: Prospective Associations, High-Risk Subgroups and Possible Psychological Mechanisms. Int Rev Psychiatry 26, 189-204. (2014). doi:10.3109/09540261.2014.881330

37. Brown LA, Lynch KG, and Cheatle M. Pain Catastrophizing as a Predictor of Suicidal Ideation in Chronic Pain Patients with an Opiate Prescription. Psychiatry Res 286, 112893 (2020). doi:10.1016/j.psychres.2020.112893

38. Calandre EP, Navajas-Rojas MA, Ballesteros J, Garcia-Carrillo J, Garcia-Leiva JM, and Rico-Villademoros F. Suicidal Ideation in Patients with Fibromyalgia: a Cross-Sectional Study. Pain Pract 15, 168-74. (2015). doi:10.1111/papr.12164

39. Cahill CM, Taylor AMW, Cook C, Ong E, Morón JA, and Evans CJ. Does the Kappa Opioid Receptor System Contribute to Pain Aversion? Front Pharmacol 5, 253 (2014). doi:10.3389/fphar.2014.00253

40. Cahill CM, and Taylor AM. Neuroinflammation-a Co-occurring Phenomenon Linking Chronic Pain and Opioid Dependence. Curr Opin Behav Sci 13, 171-7. (2017). doi:10.1016/j.cobeha.2016.12.003

41. Elman I, Borsook D, and Volkow ND. Pain and Suicidality: Insights from Reward and Addiction Neuroscience. Prog Neurobiol 109, 1-27. (2013). doi:10.1016/j.pneurobio.2013.06.003

42. Nicholson B, and Verma S. Comorbidities in Chronic Neuropathic Pain. Pain Med 5 Suppl 1, S9 (2004). doi:10.1111/j.1526-4637.2004.04019.x

43. Mee S, Bunney BG, Reist C, Potkin SG, and Bunney WE. Psychological Pain: a Review of Evidence. J Psychiatr Res 40, 680-90. (2006). doi:10.1016/ j.jpsychires.2006.03.003

44. Troister T, and Holden RR. Comparing Psychache, Depression, and Hopelessness in Their Associations with Suicidality: A Test of Shneidman's Theory of Suicide. Personal Individual Differences 49, 689-93. (2010). doi:10.1016/j.paid.2010.06.006

45. Conner KR, and Ilgen MA. Substance Use Disorders and Suicidal Behavior. Int Handbook Suicide Prev in editors O'Connor R, Platt S, Gordon J, 110-23. (2016) doi:10.1002/9781118903223.ch6

46. Edwards S, Vendruscolo LF, Gilpin NW, Wojnar M, and Witkiewitz K. Alcohol and Pain: A Translational Review of Preclinical and Clinical Findings to Inform Future Treatment Strategies. Alcohol Clin Exp Res 44, 368-83. (2020). doi:10.1111/acer.14260

47. Zale EL, Maisto SA, and Ditre JW. Interrelations between Pain and Alcohol: An Integrative Review. Clin Psychol Rev 37, 57-71. (2015). doi:10.1016/ j.cpr.2015.02.005

48. Nieto SJ, Green R, Grodin EN, Cahill CM, and Ray LA. Pain Catastrophizing Predicts Alcohol Craving in Heavy Drinkers Independent of Pain Intensity. Drug and Alcohol Dependence 218, 108368 (2021). doi:10.1016/ j.drugalcdep.2020.108368

49. Panksepp J, and Biven L The Archaeology of Mind: Neuroevolutionary Origins of Human Emotions (Norton Series on Interpersonal Neurobiology). (WW Norton \& Company, 2012).

50. Panksepp J, and Watt D. Why Does Depression Hurt? Ancestral PrimaryProcess Separation-Distress (PANIC/GRIEF) and Diminished Brain Reward (SEEKING) Processes in the Genesis of Depressive Affect. Psychiatry Interpersonal Biol Process 74, 5-13. (2011). doi:10.1521/psyc.2011.74.1.5

51. Panksepp J, Herman B, Conner R, Bishop P, and Scott JP. The Biology of Social Attachments: Opiates Alleviate Separation Distress. Biol Psychiatry 13, 607-18. (1978).

52. Herman BH, and Panksepp J. Effects of Morphine and Naloxone on Separation Distress and Approach Attachment: Evidence for Opiate Mediation of Social Affect. Pharmacol Biochem Behav 9, 213-20. (1978). doi:10.1016/0091-3057(78)90167-3

53. Kalin NH, Shelton SE, and Barksdale CM. Opiate Modulation of SeparationInduced Distress in Non-human Primates. Brain Res 440, 285-92. (1988). doi:10.1016/0006-8993(88)90997-3

54. Yovell Y, Bar G, Mashiah M, Baruch Y, Briskman I, Asherov J, et al. UltraLow-Dose Buprenorphine as a Time-Limited Treatment for Severe Suicidal Ideation: A Randomized Controlled Trial. Am J Psychiatry. 173, 491-8. (2015). doi:10.1176/appi.ajp.2015.15040535

55. Karp JF, Butters MA, Begley AE, et al. Safety, Tolerability, and Clinical Effect of Low-Dose Buprenorphine for Treatment-Resistant Depression in Midlife and Older Adults. J Clin Psychiatry 75, e785-e793. (2014). doi:10.4088/jcp.13m08725

56. Richards BM. Suicide and Internalised Relationships: A Study from the Perspective of Psychotherapists Working with Suicidal Patients. $\mathrm{Br}$ J Guidance Counselling 27, 85-98. (1999). doi:10.1080/03069889908259717 
57. Gunderson JG. Borderline Patient's Intolerance of Aloneness: Insecure Attachments and Therapist Availability. Am J Psychiatry (1996).

58. Cardish RJ. Psychopharmacologic Management of Suicidality in Personality Disorders. Can J Psychiatry 52, 115S (2007).

59. Panksepp J. Feeling the Pain of Social Loss. Science 302, 237-9. (2003). doi:10.1126/science.1091062

60. Zellner MR, Watt DF, Solms M, and Panksepp J. Affective Neuroscientific and Neuropsychoanalytic Approaches to Two Intractable Psychiatric Problems: Why Depression Feels So Bad and what Addicts Really Want. Neurosci Biobehavioral Rev 35, 2000-8 (2011). doi:10.1016/j.neubiorev.2011.01.003

61. Amini-Khoei H, Amiri S, Mohammadi-Asl S, Alijanpour S, Poursaman S, Haj-Mirzaian A, et al. Experiencing Neonatal Maternal Separation Increased Pain Sensitivity in Adult Male Mice: Involvement of Oxytocinergic System. Neuropeptides 61, 77-85. (2017). doi:10.1016/j.npep.2016.11.005

62. Mizoguchi H, Fukumoto K, Sakamoto G, Jin S, Toyama A, Wang T, et al. Maternal Separation as a Risk Factor for Aggravation of Neuropathic Pain in Later Life in Mice. Behav Brain Res 359, 942-9. (2019). doi:10.1016/ j.bbr.2018.06.015

63. Burke NN, Finn DP, McGuire BE, and Roche M. Psychological Stress in Early Life as a Predisposing Factor for the Development of Chronic Pain: Clinical and Preclinical Evidence and Neurobiological Mechanisms. J Neurosci Res 95, 1257-70. (2017). doi:10.1002/jnr.23802

64. Evans S, Moloney C, Seidman LC, Zeltzer LK, and Tsao JCI. Parental Bonding in Adolescents with and without Chronic Pain. J Pediatr Psychol 43, 276-84. (2018). doi:10.1093/jpepsy/jsx110

65. Eisenberger N. The Pain of Social Disconnection: Examining the Shared Neural Underpinnings of Physical and Social Pain. Nat Rev Neurosci 13, 421-34. (2012). doi:10.1038/nrn3231

66. Watt DF, and Panksepp J. Depression: An Evolutionarily Conserved Mechanism to Terminate Separation Distress? A Review of Aminergic, Peptidergic, and Neural Network Perspectives. Neuropsychoanalysis 11, 7-51. (2009). doi:10.1080/15294145.2009.10773593

67. Eisenberger NI. The Neural Bases of Social Pain: Evidence for Shared Representations with Physical Pain. Psychosomatic Med 74, 126 (2012). doi:10.1097/psy.0b013e3182464dd1

68. Kross E, Berman MG, Mischel W, Smith EE, and Wager TD. Social Rejection Shares Somatosensory Representations with Physical Pain. Proc Natl Acad Sci 108, 6270-5. (2011). doi:10.1073/pnas.1102693108

69. Todd AJ. Neuronal Circuitry for Pain Processing in the Dorsal Horn. Nat Rev Neurosci 11, 823-36. (2010). doi:10.1038/nrn2947

70. Wercberger R, and Basbaum AI. Spinal Cord Projection Neurons: a Superficial, and Also Deep, Analysis. Curr Opin Physiol 11, 109-15. (2019). doi:10.1016/j.cophys.2019.10.002

71. Millan MJ. Descending Control of Pain. Prog Neurobiol 66, 355-474. (2002). doi:10.1016/s0301-0082(02)00009-6

72. Treede R-D, Kenshalo DR, Gracely RH, and Jones AKP. The Cortical Representation of Pain. PAIN 79, (1999). doi:10.1016/s0304-3959(98) 00184-5

73. Price DD. Psychological and Neural Mechanisms of the Affective Dimension of Pain. Science 288, 1769-72. (2000). doi:10.1126/science.288.5472.1769

74. Lumley MA, Cohen JL, Borszcz GS, Cano A, Radcliffe AA, Porter LS, et al. Pain and Emotion: a Biopsychosocial Review of Recent Research. J Clin Psychol 67, 942-68. (2011). doi:10.1002/jclp.20816

75. Spike RC, Puskár Z, Andrew D, and Todd AJ. A Quantitative and Morphological Study of Projection Neurons in Lamina I of the Rat Lumbar Spinal Cord. Eur J Neurosci 18, 2433-48. (2003). doi:10.1046/ j.1460-9568.2003.02981.x

76. Polgár E, Wright LL, and Todd AJ. A Quantitative Study of Brainstem Projections from Lamina I Neurons in the Cervical and Lumbar Enlargement of the Rat. Brain Res 1308, 58-67. (2010). doi:10.1016/ j.brainres.2009.10.041

77. Sharim J, and Pouratian N. Anterior Cingulotomy for the Treatment of Chronic Intractable Pain: A Systematic Review. Pain physician 19, 537-50. (2016).

78. O'Connor M-F, Wellisch DK, Stanton AL, Eisenberger NI, Irwin MR, Lieberman $\mathrm{MD}$, et al. Craving Love? Enduring Grief Activates Brain's Reward center. Neuroimage 42, 969-72. (2008). doi:10.1016/s0750-7658(08)00619-9
79. Berridge KC. Pleasures of the Brain. Brain Cogn 52, 106-28. (2003). doi:10.1016/s0278-2626(03)00014-9

80. Borsook D, Becerra L, Carlezon WA, Shaw M, Renshaw P, Elman I, et al. Reward-aversion Circuitry in Analgesia and Pain: Implications for Psychiatric Disorders. Eur J pain 11, 7-20. (2007). doi:10.1016/j.ejpain.2005.12.005

81. Scott DJ, Heitzeg MM, Koeppe RA, Stohler CS, and Zubieta J-K. Variations in the Human Pain Stress Experience Mediated by Ventral and Dorsal Basal Ganglia Dopamine Activity. J neuroscience: official J Soc Neurosci 26, 10789-95. (2006). doi:10.1523/jneurosci.2577-06.2006

82. Lister KC, Bouchard SM, Markova T, Aternali A, Denecli P, Pimentel SD, et al. Chronic Pain Produces Hypervigilance to Predator Odor in Mice. Curr Biology: $C B$ vol. 30 R866-R867. (2020). doi:10.1016/ j.cub.2020.06.025

83. Herman BH, and Panksepp J. Ascending Endorphin Inhibition of Distress Vocalization. Science 211, 1060-2. (1981). doi:10.1126/science.7466377

84. Panksepp J, Normansell L, Herman B, Bishop P, and Loring C. Neural and Neurochemical Control of the Separation Distress Call. in The Physiological Control of Mammalian Vocalization (ed. Newman, JD) (Springer, 1988). doi:10.1007/978-1-4613-1051-8_15

85. Eisenberger NI, Lieberman MD, and Williams KD. Does Rejection Hurt? an fMRI Study of Social Exclusion. Science 302, 290-2. (2003). doi:10.1126/ science. 1089134

86. Baliki MN, Petre B, Torbey S, Herrmann KM, Huang L, Schnitzer TJ, et al. Corticostriatal Functional Connectivity Predicts Transition to Chronic Back Pain. Nat Neurosci 15, 1117-9. (2012). doi:10.1038/nn.3153

87. Apkarian AV, Bushnell MC, Treede R-D, and Zubieta J-K. Human Brain Mechanisms of Pain Perception and Regulation in Health and Disease. Eur J Pain 9, 463 (2005). doi:10.1016/j.ejpain.2004.11.001

88. Jensen KB, Srinivasan P, Spaeth R, Tan Y, Kosek E, Petzke F, et al. Overlapping Structural and Functional Brain Changes in Patients with Long-Term Exposure to Fibromyalgia Pain. Arthritis Rheum 65, 3293-303. (2013). doi:10.1002/art.38170

89. Ichesco E, Schmidt-Wilcke T, Bhavsar R, Clauw DJ, Peltier SJ, Kim J, et al. Altered Resting State Connectivity of the Insular Cortex in Individuals with Fibromyalgia. J pain : official J Am Pain Soc 15, 815-26.(2014). doi:10.1016/ j.jpain.2014.04.007

90. Fields HL, Hjelmstad GO, Margolis EB, and Nicola SM. Ventral Tegmental Area Neurons in Learned Appetitive Behavior and Positive Reinforcement. Annu Rev Neurosci 30, 289-316. (2007). doi:10.1146/ annurev.neuro.30.051606.094341

91. Sun W. Dopamine Neurons in the Ventral Tegmental Area: Drug-Induced Synaptic Plasticity and its Role in Relapse to Drug-Seeking Behavior. Curr Drug Abuse Rev vol. 4 270-85. (2011). doi:10.2174/1874473711104040270

92. Boutelle MG, Zetterström T, Pei Q, Svensson L, and Fillenz M. In Vivo neurochemical Effects of Tail Pinch. J Neurosci Methods 34, 151-7. (1990). doi:10.1016/0165-0270(90)90053-i

93. Wood PB, Schweinhardt P, Jaeger E, Dagher A, Hakyemez A, Rabiner EA, et al. Fibromyalgia Patients Show an Abnormal Dopamine Response to Pain. Eur J Neurosci 25, 3576-82. (2007). doi:10.1111/j.1460-9568.2007.05623.x

94. Geha PY, Baliki MN, Wang X, Harden RN, Paice JA, Apkarian AV, et al. Brain Dynamics for Perception of Tactile Allodynia (Touch-induced Pain) in Postherpetic Neuralgia. Pain 138, 641-56. (2008). doi:10.1016/j.pain.2008.02.021

95. Pais-Vieira M, Mendes-Pinto MM, Lima D, and Galhardo V. Cognitive Impairment of Prefrontal-dependent Decision-Making in Rats after the Onset of Chronic Pain. Neuroscience 161, 671-9. (2009). doi:10.1016/ j.neuroscience.2009.04.011

96. Mansour A, Khachaturian H, Lewis ME, Akil H, and Watson SJ. Anatomy of CNS Opioid Receptors. Trends Neurosciences 11, 308-14. (1988). doi:10.1016/0166-2236(88)90093-8

97. Kieffer BL, and Gavériaux-Ruff C. Exploring the Opioid System by Gene Knockout. Prog Neurobiol 66, 285-306. (2002). doi:10.1016/s0301-0082(02) 00008-4

98. Simonin F, Gavériaux-Ruff C, Befort K, Matthes H, Lannes B, Micheletti G, et al. Kappa-Opioid Receptor in Humans: cDNA and Genomic Cloning, Chromosomal Assignment, Functional Expression, Pharmacology, and Expression Pattern in the central Nervous System. Proc Natl Acad Sci United States America 92, 7006-10. (1995). doi:10.1073/pnas.92.15.7006 
99. Kolesnikov Y, Jain S, Wilson R, and Pasternak GW. Peripheral k1-opioid Receptor-Mediated Analgesia in Mice. Eur J Pharmacol 310, 141-3. (1996). doi:10.1016/0014-2999(96)00520-1

100. Lutz P-E, and Kieffer BL. Opioid Receptors: Distinct Roles in Mood Disorders. Trends Neurosciences 36, 195-206. (2013). doi:10.1016/j.tins.2012.11.002

101. Darcq E, and Kieffer BL. Opioid Receptors: Drivers to Addiction? Nat Rev Neurosci 19, 499-514. (2018). doi:10.1038/s41583-018-0028-x

102. Chavkin C, and Koob GF. Dynorphin, Dysphoria, and Dependence: the Stress of Addiction. Neuropsychopharmacology: official publication of the American College of Neuropsychopharmacology 41, 373-4. (2016). doi:10.1038/npp.2015.258

103. Kumor KM, Haertzen CA, Johnson RE, Kocher T, and Jasinski D. Human Psychopharmacology of Ketocyclazocine as Compared with Cyclazocine, Morphine and Placebo. J Pharmacol Exp Ther 238, 960-8. (1986).

104. Pfeiffer A, Brantl V, Herz A, and Emrich HM. Psychotomimesis Mediated by Kappa Opiate Receptors. Science 233, 774-6. (1986). doi:10.1126/science.3016896

105. Wadenberg M-LG. A Review of the Properties of Spiradoline: a Potent and Selective Kappa-Opioid Receptor Agonist. CNS Drug Rev 9, 187-98. (2003). doi:10.1111/j.1527-3458.2003.tb00248.x

106. Negus SS, Morrissey EM, Rosenberg M, Cheng K, and Rice KC. Effects of Kappa Opioids in an Assay of Pain-Depressed Intracranial Self-Stimulation in Rats. Psychopharmacology 210, 149-59. (2010). doi:10.1007/s00213-009-1770-6

107. Carlezon WA, Béguin C, DiNieri JA, Baumann MA, Richards MR, Todtenkopf MS, et al. Depressive-Like Effects of the $\kappa$-Opioid Receptor Agonist Salvinorin A on Behavior and Neurochemistry in Rats. J Pharmacol Exp Ther 316, 440-7.(2006). doi:10.1124/jpet.105.092304

108. Todtenkopf MS, Marcus JF, Portoghese PS, and Carlezon WA. Effects of $\kappa$-opioid Receptor Ligands on Intracranial Self-Stimulation in Rats. Psychopharmacology 172, 463-70. (2004). doi:10.1007/s00213-003-1680-y

109. Land BB, Bruchas MR, Lemos JC, Xu M, Melief EJ, Chavkin C, et al. The Dysphoric Component of Stress Is Encoded by Activation of the Dynorphin Kappa-Opioid System. J neuroscience: official J Soc Neurosci 28, 407-14. (2008). doi:10.1523/ineurosci.4458-07.2008

110. Wee S, and Koob GF. The Role of the Dynorphin-к Opioid System in the Reinforcing Effects of Drugs of Abuse. Psychopharmacology 210, 121-35. (2010). doi:10.1007/s00213-010-1825-8

111. Carr KD, and Bak TH. Medial Thalamic Injection of Opioid Agonists: MuAgonist Increases while Kappa-Agonist Decreases Stimulus Thresholds for Pain and Reward. Brain Res 441, 173-84. (1988). doi:10.1016/0006-8993(88)91396-0

112. Rasakham K, and Liu-Chen L-Y. Sex Differences in Kappa Opioid Pharmacology. Life Sci 88, 2-16. (2011). doi:10.1016/j.lfs.2010.10.007

113. Chartoff EH, and Mavrikaki M. Sex Differences in Kappa Opioid Receptor Function and Their Potential Impact on Addiction. Front Neurosci 9, 466 (2015). doi:10.3389/fnins.2015.00466

114. Fullerton EF, Doyle HH, and Murphy AZ. Impact of Sex on Pain and Opioid Analgesia: a Review. Curr Opin Behav Sci 23, 183-90. (2018). doi:10.1016/ j.cobeha.2018.08.001

115. Panksepp J, Herman BH, Vilberg T, Bishop P, and DeEskinazi FG. Endogenous Opioids and Social Behavior. Neurosci Biobehavioral Rev 4, 473-87. (1980). doi:10.1016/0149-7634(80)90036-6

116. Nelson EE, and Panksepp J. Brain Substrates of Infant-Mother Attachment: Contributions of Opioids, Oxytocin, and Norepinephrine. Neurosci Biobehavioral Rev 22, 437-52. (1998). doi:10.1016/s0149-7634(97)00052-3

117. Shoemaker WJ, and Kehoe P. Effect of Isolation Conditions on Brain Regional Enkephalin And !b-Endorphin Levels and Vocalizations in 10-Day-Old Rat Pups. Behav Neurosci vol. 109 117-22. (1995). doi:10.1037/0735-7044.109.1.117

118. Kehoe P, and Boylan CB. Behavioral Effects of Kappa-Opioid-Receptor Stimulation on Neonatal Rats. Behav Neurosci vol. 108 418-23. (1994). doi:10.1037/0735-7044.108.2.418

119. Kehoe P, and Blass EM. Opioid-mediation of Separation Distress in 10-DayOld Rats: Reversal of Stress with Maternal Stimuli. Developmental Psychobiology 19, 385-98. (1986). doi:10.1002/dev.420190410

120. Peckys D, and Landwehrmeyer GB. Expression of Mu, Kappa, and delta Opioid Receptor Messenger RNA in the Human CNS: a 33P In Situ Hybridization Study. Neuroscience 88, 1093-135. (1999). doi:10.1016/ s0306-4522(98)00251-6

121. Mansour A, Burke S, Pavlic RJ, Akil H, and Watson SJ. Immunohistochemical Localization of the Cloned $\kappa 1$ Receptor in the Rat
CNS and Pituitary. Neuroscience 71, 671-90. (1996). doi:10.1016/03064522(95)00464-5

122. Margolis EB, Lock H, Chefer VI, Shippenberg TS, Hjelmstad GO, Fields HL, et al. Kappa Opioids Selectively Control Dopaminergic Neurons Projecting to the Prefrontal Cortex. J Neurosci 103, 2938-42. (2006). doi:10.1073/ pnas.0511159103

123. Margolis EB, Hjelmstad GO, Bonci A, and Fields HL. Both Kappa and Mu Opioid Agonists Inhibit Glutamatergic Input to Ventral Tegmental Area Neurons. J Neurophysiol 93, 3086-93. (2005). doi:10.1152/jn.00855.2004

124. Margolis EB, Hjelmstad GO, Bonci A, and Fields HL Kappa-opioid Agonists Directly Inhibit Midbrain Dopaminergic Neurons. J neuroscience: official J Soc Neurosci 23, 9981-6. (2003). doi:10.1523/jneurosci.23-31-09981.2003

125. Ford CP, Beckstead MJ, and Williams JT. Kappa Opioid Inhibition of Somatodendritic Dopamine Inhibitory Postsynaptic Currents. J Neurophysiol 97, 883-91. (2007). doi:10.1152/jn.00963.2006

126. Donzanti BA, Althaus JS, Payson MM, and Von Voigtlander PF. Kappa Agonist-Induced Reduction in Dopamine Release: Site of Action and Tolerance. Res Commun Chem Pathol Pharmacol 78, 193-210. (1992).

127. Spanagel R, Herz A, and Shippenberg TS. Opposing Tonically Active Endogenous Opioid Systems Modulate the Mesolimbic Dopaminergic Pathway. Proc Natl Acad Sci United States America 89, 2046-50. (1992). doi:10.1073/pnas.89.6.2046

128. Heijna MH, Padt M, Hogenboom F, Portoghese PS, Mulder AH, Schoffelmeer AN, et al. Opioid Receptor-Mediated Inhibition of Dopamine and Acetylcholine Release from Slices of Rat Nucleus Accumbens, Olfactory Tubercle and Frontal Cortex. Eur J Pharmacol 181, 267-78. (1990). doi:10.1016/0014-2999(90)90088-n

129. Ehrich JM, Turncliff R, Du Y, Leigh-Pemberton R, Fernandez E, Jones R, et al. Kappa Opioid Receptor-Induced Aversion Requires P38 MAPK Activation in VTA Dopamine Neurons. J neuroscience : official J Soc Neurosci 35, 12917-31. (2015). doi:10.1523/jneurosci.2444-15.2015

130. Narita M, Suzuki T, Funada M, Misawa M, and Nagase H. Blockade of the Morphine-Induced Increase in Turnover of Dopamine on the Mesolimbic Dopaminergic System by Kappa-Opioid Receptor Activation in Mice. Life Sci 52, 397-404. (1993). doi:10.1016/0024-3205(93)90153-t

131. Shippenberg TS, Bals-Kubik R, and Herz A. Examination of the Neurochemical Substrates Mediating the Motivational Effects of Opioids: Role of the Mesolimbic Dopamine System and D-1 vs. D-2 Dopamine Receptors. J Pharmacol Exp Ther 265, 53-9. (1993).

132. Chefer VI, Bäckman CM, Gigante ED, and Shippenberg TS. Kappa Opioid Receptors on Dopaminergic Neurons Are Necessary for Kappa-Mediated Place Aversion. Neuropsychopharmacology 38, 2623-31. (2013). doi:10.1038/ npp.2013.171

133. Elman I, and Borsook D. Common Brain Mechanisms of Chronic Pain and Addiction. Neuron 89, 11-36. (2016). doi:10.1016/j.neuron.2015.11.027

134. Taylor AMW, Becker S, Schweinhardt P, and Cahill C. Mesolimbic Dopamine Signaling in Acute and Chronic Pain: Implications for Motivation, Analgesia, and Addiction. Pain 157, 1194-8. (2016). doi:10.1097/j.pain.0000000000000494

135. Elman I, Borsook D, and Volkow ND. Pain and Suicidality: Insights from Reward and Addiction Neuroscience. Prog Neurobiol 109, 1-27. (2013). doi:10.1016/j.pneurobio.2013.06.003

136. Massaly N, Copits BA, Wilson-Poe AR, Hipólito L, Markovic T, Yoon HJ, et al. Pain-Induced Negative Affect Is Mediated via Recruitment of the Nucleus Accumbens Kappa Opioid System. Neuron 102, 564-73.e6 (2019). doi:10.1016/j.neuron.2019.02.029

137. Cahill CM, Lueptow L, Kim H, Shusharla R, Bishop A, et al. Kappa Opioid Signaling at the Crossroads of Chronic Pain and Opioid Addiction. Handbook of Experimental Pharmacology (2021) doi:10.1007/164_2021_434

138. Koob GF. Drug Addiction: Hyperkatifeia/Negative Reinforcement as a Framework for Medications Development. Pharmacol Rev 73, 163-201. (2021). doi:10.1124/pharmrev.120.000083

139. Zhou Y, Colombo G, Gessa GL, and Kreek MJ. Effects of Voluntary Alcohol Drinking on Corticotropin-Releasing Factor and Preprodynorphin mRNA Levels in the central Amygdala of Sardinian Alcohol-Preferring Rats. Neurosci Lett 554, 110-4. (2013). doi:10.1016/j.neulet.2013.08.071

140. Rose JH, Karkhanis AN, Chen R, Gioia D, Lopez MF, Becker HC, et al. Supersensitive Kappa Opioid Receptors Promotes Ethanol Withdrawal- 
Related Behaviors and Reduce Dopamine Signaling in the Nucleus Accumbens. Int J Neuropsychopharmacol 19, (2016). doi:10.1093/ijnp/pyv127

141. Anderson RI, Lopez MF, Griffin WC, Haun HL, Bloodgood DW, Pati D, et al. Dynorphin-kappa Opioid Receptor Activity in the central Amygdala Modulates Binge-like Alcohol Drinking in Mice. Neuropsychopharmacology 44, 1084-92. (2019). doi:10.1038/s41386-018-0294-3

142. Ciccocioppo R, Economidou D, Rimondini R, Sommer W, Massi M, Heilig $\mathrm{M}$, et al. Buprenorphine Reduces Alcohol Drinking through Activation of the Nociceptin/Orphanin FQ-NOP Receptor System. Biol Psychiatry 61, 4-12. (2007). doi:10.1016/j.biopsych.2006.01.006

143. Schank JR, Goldstein AL, Rowe KE, King CE, Marusich JA, Wiley JL, et al. The Kappa Opioid Receptor Antagonist JDTic Attenuates Alcohol Seeking and Withdrawal Anxiety. Addict Biol 17, 634-47. (2012). doi:10.1111/j.13691600.2012.00455.x

144. Walker BM, Zorrilla EP, and Koob GF. Systemic k-opioid Receptor Antagonism by Nor-Binaltorphimine Reduces Dependence-Induced Excessive Alcohol Self-Administration in Rats. Addict Biol 16, 116-9. (2011). doi:10.1111/j.1369-1600.2010.00226.x

145. Walker BM, Rasmussen DD, Raskind MA, and Koob GF. a1-noradrenergic Receptor Antagonism Blocks Dependence-Induced Increases in Responding for Ethanol. Alcohol 42, 91-7. (2008). doi:10.1016/j.alcohol.2007.12.002

146. Nealey KA, Smith AW, Davis SM, Smith DG, and Walker BM. к-Opioid Receptors Are Implicated in the Increased Potency of Intra-accumbens Nalmefene in Ethanol-dependent Rats. Neuropharmacology 61, 35-42. (2011). doi:10.1016/j.neuropharm.2011.02.012

147. Domi E, Barbier E, Augier E, Augier G, Gehlert D, Barchiesi R, et al. Preclinical Evaluation of the Kappa-Opioid Receptor Antagonist CERC501 as a Candidate Therapeutic for Alcohol Use Disorders. Neuropsychopharmacology 43, 1805-12. (2018). doi:10.1038/s41386-0180015-y

148. Coplan PM, Sessler NE, Harikrishnan V, Singh R, and Perkel C. Comparison of Abuse, Suspected Suicidal Intent, and Fatalities Related to the 7-day Buprenorphine Transdermal Patch versus Other Opioid Analgesics in the National Poison Data System. Postgrad Med 129, 55-61. (2017). doi:10.1080/ 00325481.2017 .1269596

149. Bodkin JA, Zornberg GL, Lukas SE, and Cole JO. Buprenorphine Treatment of Refractory Depression. J Clin Psychopharmacol 15, (1995). doi:10.1097/ 00004714-199502000-00008

150. Emrich HM, Vogt P, Herz A, and Kissling W. Antidepressant Effects of Buprenorphine. Lancet 2, 709 (1982). doi:10.1016/s0140-6736(82)90727-9

151. Thomas R, Kosten M, Charles Morgan M, Therese A, and Kosten P. Depressive Symptoms during Buprenorphine Treatment of Opioid Abusers. J Substance Abuse Treat 7, 51-4. (1990). doi:10.1016/07405472(90)90035-o

152. Nyhuis PW, Gastpar M, and Norbert S. Opiate Treatment in Depression Refractory to Antidepressants and Electroconvulsive Therapy. J Clin Psychopharmacol 28, 593-5. (2008). doi:10.1097/jcp.0b013e31818638a4

153. Serafini G, Adavastro G, Canepa G, De Berardis D, Valchera A, Pompili M, et al. The Efficacy of Buprenorphine in Major Depression, TreatmentResistant Depression and Suicidal Behavior: A Systematic Review. Int J Mol Sci 19, 2410 (2018). doi:10.3390/ijms19082410

154. Lutfy K, and Cowan A. Buprenorphine: a Unique Drug with Complex Pharmacology. Curr neuropharmacology 2, 395-402. (2004). doi:10.2174/ 1570159043359477

155. Huang P, Kehner GB, Cowan A, and Liu-Chen LY. Comparison of Pharmacological Activities of Buprenorphine and Norbuprenorphine: Norbuprenorphine Is a Potent Opioid Agonist. J Pharmacol Exp Ther 297, 688-95. (2001).

156. Wentland MP, Lou R, Lu Q, Bu Y, VanAlstine MA, et al. Syntheses and Opioid Receptor Binding Properties of Carboxamido-Substituted Opioids. Bioorg Med Chem Lett 19, 203-8. (2009). doi:10.1016/j.bmcl.2008.10.134

157. Dunn AD, Reed B, Erazo J, Ben-Ezra A, and Kreek MJ. Signaling Properties of Structurally Diverse Kappa Opioid Receptor Ligands: Toward In Vitro Models of In Vivo Responses. ACS Chem Neurosci 10, 3590-600. (2019). doi:10.1021/acschemneuro.9b00195

158. Robinson SE. Buprenorphine: An Analgesic with an Expanding Role in the Treatment of Opioid Addiction. CNS Drug Rev 8, 377-90. (2002). doi:10.1111/j.1527-3458.2002.tb00235.x
159. Striebel JM, and Kalapatapu RK. The Anti-suicidal Potential of Buprenorphine: A Case Report. Int J Psychiatry Med 47, 169-74. (2014). doi:10.2190/pm.47.2.g

160. Ahmadi J. The Effect of Buprenorphine on the Reduction of Cannabis and Heroin Craving and Suicidal Thoughts: a New Finding. Insights Biomed 1, 2 (2016).

161. Benhamou O-M, Lynch S, and Klepacz L. Case Report: Buprenorphine-A Treatment for Psychological Pain and Suicidal Ideation? Am J Addict vol. 30 80-2. (2021). doi:10.1111/ajad.13063

162. Gibbs HM, Price D, Delgado PL, Clothier JL, and Cáceda R. Buprenorphine Use for Pain and Suicidal Ideation in Severely Suicidal Patients. Int J Psychiatry Med (2020) doi:10.1177/0091217420913396

163. Ahmadi J, Jahromi MS, and Ehsaei Z. The Effectiveness of Different Singly Administered High Doses of Buprenorphine in Reducing Suicidal Ideation in Acutely Depressed People with Co-morbid Opiate Dependence: a Randomized, Double-Blind, Clinical Trial. Trials 19, 462 (2018). doi:10.1186/s13063-018-2843-9

164. Fava M, Memisoglu A, Thase ME, Bodkin JA, Trivedi MH, de Somer M, et al. Opioid Modulation with Buprenorphine/Samidorphan as Adjunctive Treatment for Inadequate Response to Antidepressants: A Randomized Double-Blind Placebo-Controlled Trial. Am J Psychiatry 173, 499-508. (2016). doi:10.1176/appi.ajp.2015.15070921

165. Ehrich E, Turncliff R, Du Y, Leigh-Pemberton R, Fernandez E, Jones R, et al. Evaluation of Opioid Modulation in Major Depressive Disorder. Neuropsychopharmacology 40, 1448-55. (2015). doi:10.1038/npp.2014.330

166. Castagné V, Moser P, Roux S, and Porsolt RD. Rodent Models of Depression: Forced Swim and Tail Suspension Behavioral Despair Tests in Rats and Mice. Curr Protoc Neurosci 55, 8-10. (2011). doi:10.1002/0471142301.ns0810as55

167. Porsolt RD, le Pichon M, and Jalfre M. Depression: a New Animal Model Sensitive to Antidepressant Treatments. Nature 266, 730-2. (1977). doi:10.1038/266730a0

168. Dulawa SC, and Hen R. Recent Advances in Animal Models of Chronic Antidepressant Effects: the novelty-induced Hypophagia Test. Neurosci Biobehavioral Rev 29, 771-83. (2005). doi:10.1016/j.neubiorev.2005.03.017

169. Bodnoff SR, Suranyi-Cadotte B, Quirion R, and Meaney MJ. A Comparison of the Effects of Diazepam versus Several Typical and Atypical Anti-depressant Drugs in an Animal Model of Anxiety. Psychopharmacology 97, 277-9. (1989). doi:10.1007/bf00442264

170. Bodnoff SR, Suranyi-Cadotte B, Aitken DH, Quirion R, and Meaney MJ. The Effects of Chronic Antidepressant Treatment in an Animal Model of Anxiety. Psychopharmacology 95, 298-302. (1988). doi:10.1007/BF00181937

171. Falcon E, Maier K, Robinson SA, Hill-Smith TE, and Lucki I. Effects of Buprenorphine on Behavioral Tests for Antidepressant and Anxiolytic Drugs in Mice. Psychopharmacology 232, 907-15. (2015). doi:10.1007/s00213-014-3723-y

172. Browne CA, van Nest DS, and Lucki I. Antidepressant-like Effects of Buprenorphine in Rats Are Strain Dependent. Behav Brain Res 278, 385-92. (2015). doi:10.1016/j.bbr.2014.10.014

173. Almatroudi A, Husbands SM, Bailey CP, and Bailey SJ. Combined Administration of Buprenorphine and Naltrexone Produces Antidepressant-like Effects in Mice. J Psychopharmacol 29, 812-21. (2015). doi:10.1177/0269881115586937

174. Smith KL, Cunningham JL, Eyerman DJ, Dean RL, Deaver DR, Sanchez C, et al. Opioid System Modulators Buprenorphine and Samidorphan Alter Behavior and Extracellular Neurotransmitter Concentrations in the Wistar Kyoto Rat. Neuropharmacology 146, 316-26. (2019). doi:10.1016/ j.neuropharm.2018.11.015

175. Robinson SA, Erickson RL, Browne CA, and Lucki I. A Role for the Mu Opioid Receptor in the Antidepressant Effects of Buprenorphine. Behav Brain Res 319, 96-103. (2017). doi:10.1016/j.bbr.2016.10.050

176. Browne CA, Erickson RL, Blendy JA, and Lucki I. Genetic Variation in the Behavioral Effects of Buprenorphine in Female Mice Derived from a Murine Model of the OPRM1 A118G Polymorphism. Neuropharmacology 117, 401-7. (2017). doi:10.1016/j.neuropharm.2017.02.005

177. Nobile B, Ramoz N, Jaussent I, Gorwood P, Olié E, Castroman JL, et al. Polymorphism A118G of Opioid Receptor Mu 1 (OPRM1) Is Associated with Emergence of Suicidal Ideation at Antidepressant Onset in a Large Naturalistic Cohort of Depressed Outpatients. Scientific Rep 9, 2569 (2019). doi:10.1038/s41598-019-39622-3 
178. Slavich GM, Tartter MA, Brennan PA, and Hammen C. Endogenous Opioid System Influences Depressive Reactions to Socially Painful Targeted Rejection Life Events. Psychoneuroendocrinology 49, 141-9. (2014). doi:10.1016/j.psyneuen.2014.07.009

179. Falcon E, Browne CA, Leon RM, Fleites VC, Sweeney R, Kirby LG, et al. Antidepressant-like Effects of Buprenorphine Are Mediated by Kappa Opioid Receptors. Neuropsychopharmacology 41, 2344-51. (2016). doi:10.1038/ npp. 2016.38

180. Lazenka ML, Moerke MJ, Townsend EA, Freeman KB, Carrol FI, Negus SS, et al. Dissociable Effects of the Kappa Opioid Receptor Agonist Nalfurafine on Pain/itch-Stimulated and Pain/itch-Depressed Behaviors in Male Rats. Psychopharmacology 235, 203-13. (2018). doi:10.1007/s00213-017-4758-7

181. Tejeda HA, Counotte DS, Oh E E, Ramamoorthy S, Schultz-Kuszak KN, Bäckman CM, et al. Prefrontal Cortical Kappa-Opioid Receptor Modulation of Local Neurotransmission and Conditioned Place Aversion. Neuropsychopharmacology 38, 1770-9. (2013). doi:10.1038/npp.2013.76

182. Liu SS, Pickens S, Burma NE, Ibarra-Lecue I, Yang H, Xue L, et al. Kappa Opioid Receptors Drive a Tonic Aversive Component of Chronic Pain. J neuroscience: official J Soc Neurosci 39, 4162-78. (2019). doi:10.1523/ jneurosci.0274-19.2019

183. McLaughlin JP, Marton-Popovici M, and Chavkin C. $\kappa$ Opioid Receptor Antagonism and Prodynorphin Gene Disruption Block Stress-Induced Behavioral Responses. J Neurosci 23, 5674 LP - 5683 (2003). doi:10.1523/ jneurosci.23-13-05674.2003

184. Mague SD, Pliakas AM, Tomasiewicz HC, Zhang Y, Stevens WC Jr, Jones RM, et al. Antidepressant-like Effects of k-opioid Receptor Antagonists in the Forced Swim Test in Rats. J Pharmacol Exp Ther 305, 323-30. (2003). doi:10.1124/jpet.102.046433

185. Carr GV, Bangasser DA, Bethea T, Young M, Valentino RJ, Lucki I, et al. Antidepressant-like Effects of $\kappa$-opioid Receptor Antagonists in Wistar Kyoto Rats. Neuropsychopharmacology 35, 752-63. (2010). doi:10.1038/ npp.2009.183

186. Chartoff E, Sawyer A, Rachlin A, Potter D, Pliakas A, Carlezon WA, et al. Blockade of Kappa Opioid Receptors Attenuates the Development of Depressive-like Behaviors Induced by Cocaine Withdrawal in Rats. Neuropharmacology 62, 167-76. (2012). doi:10.1016/j.neuropharm.2011.06.014

187. Beardsley PM, Howard JL, Shelton KL, and Carroll FI. Differential Effects of the Novel Kappa Opioid Receptor Antagonist, JDTic, on Reinstatement of Cocaine-Seeking Induced by Footshock Stressors vs Cocaine Primes and its Antidepressant-like Effects in Rats. Psychopharmacology 183, 118 (2005). doi:10.1007/s00213-005-0167-4

188. Reindl JD, Rowan K, Carey AN, Peng X, Neumeyer JL, McLaughlin JP, et al. Antidepressant-Like Effects of the Novel Kappa Opioid Antagonist MCL144B in the Forced-Swim Test. Pharmacology 81, 229-35. (2008). doi:10.1159/000112867

189. Tejedor-Real P, Mico JA, Maldonado R, Roques BP, and Gibert-Rahola J, J. Implication of Endogenous Opioid System in the Learned Helplessness Model of Depression. Pharmacol Biochem Behav 52, 145-52. (1995). doi:10.1016/0091-3057(95)00067-7

190. Berrocoso E, Ikeda K, Sora I, Uhl GR, Sánchez-Blázquez P, Mico JA, et al. Active Behaviours Produced by Antidepressants and Opioids in the Mouse Tail Suspension Test. Int J Neuropsychopharmacol 16, 151-62. (2013). doi:10.1017/s1461145711001842

191. Negus SS, Neddenriep B, Altarifi AA, Carroll FI, Leitl MD, Miller LL, et al. Effects of Ketoprofen, Morphine, and Kappa Opioids on Pain-Related Depression of Nesting in Mice. Pain 156, 1153-60. (2015). doi:10.1097/ j.pain.0000000000000171

192. Yoo J-H, Lee S-Y, Loh HH, Ho IK, and Jang C-G. Altered Emotional Behaviors and the Expression of 5-HT1A and M1 Muscarinic Receptors in $\mu$-opioid Receptor Knockout Mice. Synapse 54, 72-82. (2004). doi:10.1002/ syn. 20067
193. Filliol D, Ghozland S, Chluba J, Martin M, Matthes HW, Simonin F, et al. Mice Deficient for $\delta$ - and $\mu$-opioid Receptors Exhibit Opposing Alterations of Emotional Responses. Nat Genet 25, 195-200. (2000). doi:10.1038/76061

194. Chilcoat HD, Amick HR, Sherwood MR, and Dunn KE. Buprenorphine in the United States: Motives for Abuse, Misuse, and Diversion. J substance abuse Treat 104, 148-57. (2019). doi:10.1016/j.jsat.2019.07.005

195. Taylor GT, and Manzella F. Kappa Opioids, Salvinorin A and Major Depressive Disorder. Curr Neuropharmacol 14, 165-76. (2016). doi:10.2174/1570159x13666150727220944

196. Ranganathan M, Schnakenberg A, Skosnik PD, Cohen BM, Pittman B, Sewell RA, et al. Dose-related Behavioral, Subjective, Endocrine, and Psychophysiological Effects of Theкopioid Agonist Salvinorin A in Humans. Biol Psychiatry 72, 871-9. (2012). doi:10.1016/j.biopsych.2012.06.012

197. Pfeiffer A, Brantl V, Herz A, and Emrich HM. Psychotomimesis Mediated by Kappa Opiate Receptors. Science 233, 774 LP - 776 (1986). doi:10.1126/ science. 3016896

198. Harden MT, Smith SE, Niehoff JA, McCurdy CR, and Taylor GT. Antidepressive Effects of the $\kappa$-opioid Receptor Agonist Salvinorin A in a Rat Model of Anhedonia. Behav Pharmacol 23, 710-5. (2012). doi:10.1097/ fbp.0b013e3283586189

199. Shirayama Y, Ishida A, Iwata M, Hazama GI, Kawahara R, Duman RS, et al. Stress Increases Dynorphin Immunoreactivity in Limbic Brain Regions and Dynorphin Antagonism Produces Antidepressant-like Effects. J Neurochem 90, 1258-68. (2004). doi:10.1111/j.1471-4159.2004.02589.x

200. Navratilova E, Ji G, Phelps C, Qu C, Hein M, Yakhnitsa V, et al. Kappa Opioid Signaling in the central Nucleus of the Amygdala Promotes Disinhibition and Aversiveness of Chronic Neuropathic Pain. Pain 160, 824-32. (2019). doi:10.1097/j.pain.0000000000001458

201. Lalanne L, Ayranci G, Filliol D, Gavériaux-Ruff C, Befort K, Kieffer BL, et al. Kappa Opioid Receptor Antagonism and Chronic Antidepressant Treatment Have Beneficial Activities on Social Interactions and Grooming Deficits during Heroin Abstinence. Addict Biol 22, 1010-21. (2017). doi:10.1111/ adb. 12392

202. Lutz P-E, Ayranci G, Chu-Sin-Chung P, Matifas A, Koebel P, Filliol D, et al. Distinct Mu, Delta, and Kappa Opioid Receptor Mechanisms Underlie Low Sociability and Depressive-laike Behaviors during Heroin Abstinence. Neuropsychopharmacology 39, 2694-705. (2014). doi:10.1038/npp.2014.126

203. Berrocoso E, and Mico J-A. Cooperative Opioid and Serotonergic Mechanisms Generate superior Antidepressant-like Effects in a Mice Model of Depression. Int J Neuropsychopharmacol 12, 1033-44. (2009). doi:10.1017/s1461145709000236

204. Rojas-Corrales MO, Berrocoso E, Gibert-Rahola J, and Micó JA. Antidepressant-like Effects of Tramadol and Other central Analgesics with Activity on Monoamines Reuptake, in Helpless Rats. Life Sci 72, 143-52. (2002). doi:10.1016/s0024-3205(02)02220-8

205. Yang Q-Z, Lu SS, Tian XZ, Yang AM, Ge WW, Chen Q, et al. The Antidepressant-like Effect of Human Opiorphin via Opioid-dependent Pathways in Mice. Neurosci Lett 489, 131-5. (2011). doi:10.1016/ j.neulet.2010.12.002

206. Mansour A, Khachaturian H, Lewis ME, Akil H, and Watson SJ. Autoradiographic Differentiation of $\mathrm{Mu}$, delta, and Kappa Opioid Receptors in the Rat Forebrain and Midbrain. J neuroscience : official J Soc Neurosci 7, 2445-64. (1987).

Copyright $(2021$ Cameron, Nieto, Bosler, Wong, Bishop, Mooney and Cahill. This is an open-access article distributed under the terms of the Creative Commons Attribution License (CC BY). The use, distribution or reproduction in other forums is permitted, provided the original author(s) and the copyright owner(s) are credited and that the original publication in this journal is cited, in accordance with accepted academic practice. No use, distribution or reproduction is permitted which does not comply with these terms. 